\title{
Satellite remote sensing of a low-salinity water plume in the East China Sea
}

\author{
Y. H. Ahn, P. Shanmugam, J. E. Moon, and J. H. Ryu \\ Ocean Satellite Research Group, Korea Ocean Research and Development Institute, Ansan, P.O. Box 29, Seoul 425-600, \\ Korea
}

Received: 21 April 2008 - Revised: 8 July 2008 - Accepted: 17 July 2008 - Published: 28 July 2008

\begin{abstract}
With the aim to map and monitor a low-salinity water (LSW) plume in the East China Sea (ECS), we developed more robust and proper regional algorithms from large in-situ measurements of apparent and inherent optical properties (i.e. remote sensing reflectance, $R_{r s}$, and absorption coefficient of coloured dissolved organic matter, $\left.a_{\mathrm{CDOM}}\right)$ determined in ECS and neighboring waters. Using the above data sets, we derived the following relationships between visible $R_{r s}$ and absorption by CDOM, i.e. $R_{r s}(412) / R_{r s}(555)$ vs. $a_{\mathrm{CDOM}}(400)\left(\mathrm{m}^{-1}\right)$ and $a_{\mathrm{CDOM}}(412)\left(\mathrm{m}^{-1}\right)$ with a correlation coefficient $R^{2} 0.67$ greater than those noted for $R_{r s}$ (443)/ $R_{r s}$ (555) and $R_{r s}(490) / R_{r s}$ (555) vs. $a_{\mathrm{CDOM}}$ (400) $\left(\mathrm{m}^{-1}\right)$ and $a_{\mathrm{CDOM}}(412)\left(\mathrm{m}^{-1}\right)$. Determination of $a_{\mathrm{CDOM}}$ $\left(\mathrm{m}^{-1}\right)$ at $400 \mathrm{~nm}$ and $412 \mathrm{~nm}$ is particularly necessary to describe its absorption as a function of wavelength $\lambda$ using a single exponential model in which the spectral slope $S$ as a proxy for CDOM composition is estimated by the ratio of $a_{\mathrm{CDOM}}$ at $412 \mathrm{~nm}$ and $400 \mathrm{~nm}$ and the reference is explained simply by $a_{\mathrm{CDOM}}$ at $412 \mathrm{~nm}$. In order to derive salinity from the absorption coefficient of CDOM, in-situ measurements of salinity made in a wide range of water types from dense oceanic to light estuarine/coastal systems were used along with in-situ measurements of $a_{\mathrm{CDOM}}$ at $400 \mathrm{~nm}, 412 \mathrm{~nm}$, $443 \mathrm{~nm}$ and $490 \mathrm{~nm}$. The CDOM absorption at $400 \mathrm{~nm}$ was better inversely correlated $\left(R^{2}=0.86\right)$ with salinity than at $412 \mathrm{~nm}, 443 \mathrm{~nm}$ and $490 \mathrm{~nm}\left(R^{2}=0.85-0.66\right)$, and this correlation corresponded best with an exponential $\left(R^{2}=0.98\right)$ rather than a linear function of salinity measured in a variety of water types from this and other regions. Validation against a discrete in-situ data set showed that empirical algorithms derived from the above relationships could be successfully applied to satellite data over the range of water types for which they have been developed. Thus, we applied these algorithms to a series of SeaWiFS images for the derivation
\end{abstract}

Correspondence to: P. Shanmugam

(pshanmugam90@hotmail.com) of CDOM and salinity in the context of operational mapping and monitoring of the springtime evolution of LSW plume in the ECS. The results were very encouraging and showed interesting features in surface CDOM and salinity fields in the vicinity of the Yangtze River estuary and its offshore domains, when a regional atmospheric correction (SSMM) was employed instead of the standard (global) SeaWiFS algorithm (SAC) which revealed large errors around the edges of clouds/aerosols while masking out the nearshore areas. Nevertheless, there was good consistency between these two atmospheric correction algorithms over the relatively clear regions with a mean difference of 0.009 in $a_{\mathrm{CDOM}}(400)\left(\mathrm{m}^{-1}\right)$ and 0.096 in salinity (psu). This study suggests the possible utilization of satellite remote sensing to assess CDOM and salinity and thus provides great potential in advancing our knowledge of the shelf-slope evolution and migration of the LSW plume properties in the ECS.

Keywords. History of geophysics (Ocean sciences) Oceanography: general (Continental shelf processes) Oceanography: physical (Currents)

\section{Introduction}

The colour of the seawater is primarily determined by the concentrations of various water constituents in both particulate and dissolved forms, namely phytoplankton and its debris, coloured dissolved organic matter and suspended sediments that are found in higher levels within low-salinity water (LSW) plume near the coast. Such LSW plume regions can be explicitly inferred from field measurements or satellite observations of coloured dissolved organic matter and salinity and can be used to study the physical, chemical and biological states of the water column (Jerlov, 1968; O'Reilly et al., 1998; Boss et al., 2001; Kahru and Mitchell, 2001;

Published by Copernicus Publications on behalf of the European Geosciences Union. 
Siegel et al., 2002; Johannessen et al., 2003; Bowers et al., 2004; Morel et al., 2007; Nelson et al., 2007).

Coloured or chromophoric dissolved organic matter (CDOM), historically described as gelbstoff or yellow substance, is the main pool of absorbing substances in water and also plays a major role in various physical, chemical and biological processes (Johannessen et al., 2003; Twardowski et al., 2004). Coastal and estuary areas typically have higher and more variable abundances of these materials which originate primarily from humic substances of terrestrial origin transported to coastal seas through rivers and runoff from the land (Chester, 1990; Nelson et al., 2007). In these areas with a large input of fresh water, CDOM thus becomes one of the major determinants of the optical properties characterized by strong absorption in the ultraviolet (UV) and blue portion of the visible spectrum (e.g. Bricaud et al., 1981; D'Sa et al., 1999). In contrast, open ocean regions are characterized by a much lesser but significant amount of CDOM, resulting mainly from heterotrophic processes near the surface (Nelson et al., 2007).

Since CDOM is generally present in much higher concentrations in coastal and estuary areas and absorbs more UV and blue light than other visible light, it is easily retrieved from satellite ocean colour observations. Interpretation of remotely sensed ocean colour has thus largely depended on the ability to establish relationships between the apparent optical properties (remote sensing reflectance $R_{r}$ ) and inherent optical properties (CDOM) (e.g. Kahru and Mitchell, 2001; Siegel et al., 2002; Johannessen et al., 2003; Bowers et al., 2004; Kowalczuk et al., 2005; Kutser et al., 2005; Doxaran et al., 2005; Moon et al., 2007). Several of these studies have confirmed by theory and measurements the existence of a tight relationship between the ratio of reflection coefficients, particularly in the blue-green part of the spectrum, and CDOM absorption $\left(a_{\mathrm{CDOM}}\right)$, and this relationship has been found to be robust and applicable to a range of water bodies in which the CDOM is present in concentrations sufficient to effect the water colour in the blue spectrum.

In this case similar to the East China Sea (ECS), where the major source for CDOM absorption is riverine runoff, one would expect $a_{\mathrm{CDOM}}$ to increase with decreasing salinity as oceanic waters dilute the riverine input. Guo et al. (2007) have observed a strong linear and inverse relationship of salinity and $a_{\mathrm{CDOM}}$ in surface waters of the Yangtze River (YR) estuary in the ECS. This relationship appears to be consistent with various previous studies in other regions (Jerlov, 1968; Monahan and Pybus, 1978; Boss et al., 2001; Bowers et al., 2000, 2004; Binding and Bowers, 2003; Moon et al., 2006). A similar relationship together with the $a_{\mathrm{CDOM}}$ - reflectance ratio relationship can therefore provide reliable estimates of salinity and CDOM in the focused YR estuary areas of the ECS using satellite ocean colour observations.

However, the ECS is much more complicated in terms of the ocean and atmospheric optical properties, and the practical implementation of the global and other regional algo- rithms to satellite measurements in this region (particularly during the spring-summer) is challenging because the water column reaches high turbidity and strongly absorbing aerosols prevail by wind from adjacent Gobi desert (Cheng et al., 2005; Shanmugam and Ahn, 2007). Limiting issues are therefore still present with the standard atmospheric correction (SAC) scheme routinely used to process full resolution $(\sim 1 \mathrm{~km} /$ pixel at nadir) ocean colour radiances from the Sea-viewing Wide Field-of-view Sensor (SeaWiFS) acquired at the KORDI-HRPT (Korea Ocean Research and Development Institute - High Resolution Picture Transmission) station (Shanmugam and Ahn, 2007). To overcome these limitations and problems, more appropriate regional algorithms are highly desired to make the satellite ocean colour data offering unrivaled utility in mapping and monitoring CDOM and salinity fields in the ECS.

Our main objectives in this paper are threefold: (1) to investigate the relationships between CDOM and remote sensing reflectance $\left(R_{r s}\right)$ ratios, and between salinity and CDOM, using a large in-situ bio-optical and salinity data set collected in surface waters of the ECS and its neighboring Yellow Sea (YS) and Korean South Sea (KSS), (2) to explore whether these relationships allow accurate mapping of CDOM and salinity fields in the LSW plume region of the ECS using SeaWiFS images, and (3) to assess the performance of regional and global atmospheric correction algorithms for delivering these products for this region. This study is the first to report these analyzes in the LSW plume region of the ECS.

\section{Study area and hydrographic characteristics}

This study focuses on the East China Sea (mean depth $<50 \mathrm{~m}$ ) which is one of the largest marginal seas extending from the western area off Jeju Island in the north to the northern area off Taiwan Island in the south, and is bounded on the east by the Kuroshio and on the west by mainland China from which it receives the huge outflow from the Yangtze River (YR). Because of its large catchment area $\left(1.94 \times 10^{6} \mathrm{~km}^{2}\right)$, the mean annual freshwater discharge is estimated to be $8.94 \times 10^{11} \mathrm{~m}^{3}$, which accounts for ca. $57 \%$ of total runoff inputs to the Chinese coastal waters, with $75 \%$ of the runoff inputs discharged during late springsummer (Guo et al., 2007). The YR estuary, extending in an elongated manner and receiving cold low-saline runoff waters mostly through its southern channel, has the continental shelf circulation system mainly comprising of three currents (Fig. 1): the Yangtze River Diluted Water (YRDW), the China Coastal Current (CCC), and the Taiwan Warm Current (TaWC) (Chen et al., 2003; Shanmugam et al., 2008). The YRDW is formed by mixing between the YR runoff and saline water, while the CCC flows southward along the Chinese coast from Bohai Gulf and is strengthened by river runoff from monsoonal rainfall during the late springsummer. In contrast, the TaWC flowing northward carries 
water with deep ocean properties (and perhaps coastal properties) originating from the Kuroshio branching and Taiwan Strait. The peak YR discharge during the late spring-summer results in the low density diluted water that floats over the high salinity oceanic water and thus a plume front develops (Beardsley et al., 1985). In these seasons, the plume spreads eastward over the broad ECS, reaching as far as Jeju Island and the shelf-break, where the Kuroshio flowing northward transports the LSW plume to the northeastern and further eastern region of this Island. This leads to extensive water exchange between the ECS and Kuroshio across the shelfbreak through frontal and other oceanic processes. Such a complex situation with a high load of YR discharge strongly influences the optical properties of estuarine surface waters in the spring-summer season.

\section{Approach}

In this approach, $a_{\mathrm{CDOM}}\left(\mathrm{m}^{-1}\right)$ at $400 \mathrm{~nm}$ and $412 \mathrm{~nm}$ are determined in order to describe its absorption as a function of wavelength $\lambda$ using a single exponential model in which the spectral slope $S$ as a proxy for CDOM composition is estimated by the ratio of $a_{\mathrm{CDOM}}$ at $412 \mathrm{~nm}$ and $400 \mathrm{~nm}$ and the reference is explained simply by $a_{\mathrm{CDOM}}$ at $412 \mathrm{~nm}$. For deriving $a_{\mathrm{CDOM}}(400)$ and $a_{\mathrm{CDOM}}$ (412), a simple power-law formula is chosen because of its good performance over the other formulas, taking advantage of decreased radiance (or reflectance) in the blue (412-490 nm) and increased radiance (or reflectance) in the green $(555 \mathrm{~nm})$ by working in terms of the ratios in these two wavelengths. As the absorption by CDOM is strong at $\lambda<500 \mathrm{~nm}$, we seek to evaluate three spectral ratios in the calculation which takes the form,

$C=\alpha\left[\frac{R_{r s}\left(\lambda_{1}\right)}{R_{r s}\left(\lambda_{2}\right)}\right]^{-\beta}$,

where $C$ represents the absorption coefficient of CDOM, i.e. $a_{\mathrm{CDOM}}$ at $400 \mathrm{~nm}$ or $412 \mathrm{~nm}, \alpha$ and $\beta$ are the regression coefficients, $\lambda_{1}=412 \mathrm{~nm}, 443 \mathrm{~nm}$ or $490 \mathrm{~nm}$, and $\lambda_{2}=555 \mathrm{~nm}$, and $R_{r s}$ is the remote sensing reflectance. This formula is effective and applies to a wide range of water types considered in various previous studies. Kahru and Mitchell (2001) derived a similar empirical formula of $a_{\mathrm{CDOM}}$ (300) from their insitu data set, wherein the normalized water-leaving radiance $\left(\mathrm{nL}_{w}\right)$ ratios $\mathrm{nL}_{w}(443) / \mathrm{nL}_{w}(520)$ for OCTS (Ocean Colour and Temperature Sensor) and $\mathrm{nL}_{w}(443) / \mathrm{nL}_{w}(510)$ for SeaWiFS are used to avoid known problems with atmospheric correction at short wavelengths. However, to produce accurate estimates of $a_{\mathrm{CDOM}}(\lambda)$ from remotely sensed data, Cullen et al. (1997) and Johannessen et al. (2003) suggested the use of the blue-green band ratio of remote sensing reflectances $\left(R_{r s}(412) / R_{r s}(555)\right)$ as a predictor of $a_{\mathrm{CDOM}}(\lambda)$ through $K_{d}$ $(\lambda)$ for the surface layer of the ocean, while others (e.g. Bowers et al., 2004; Kutser et al., 2005) proposed the linear or power-law relationships but using the red-green band ratio of

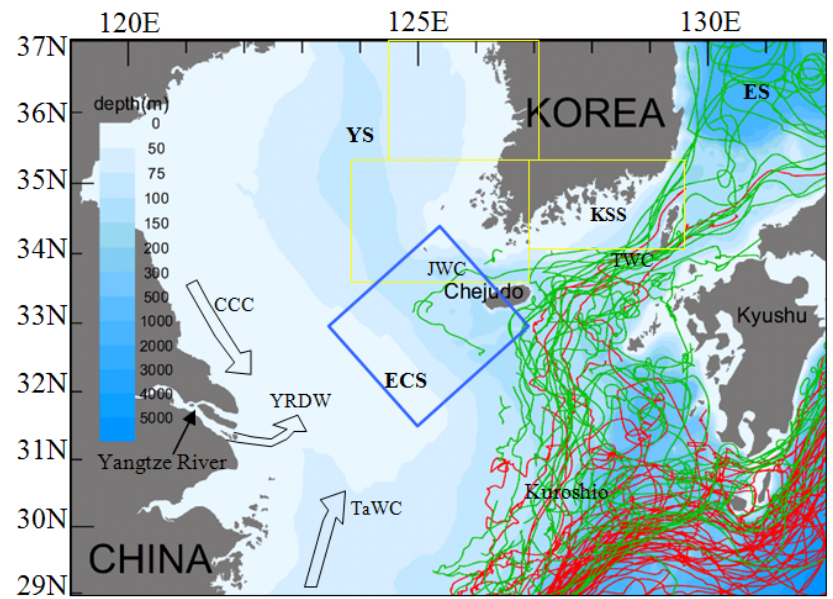

Fig. 1. A map showing the study area and sampling grids from where in-situ bio-optical data were collected during the R/V EARDO, Olympic and Tamgu cruises (1998-2005) in the Korean South Sea (KSS, R/V Olympic), Yellow Sea (YS, R/V EARDO and Tamgu) and East China Sea (ECS, R/V EARDO). The yellow and blue colour boxes represent the in-situ measurements of CDOM and salinity along with other optical measurements, respectively. YRDW - Yangtze River Diluted Water, CCC - China Coastal Current, TaWC - Taiwan Warm Current, JWC - Jeju Warm Current, TWC - Tsushima Warm Current, Kuroshio Current, ES - East Sea. The current patterns and bathymetry information came from Lie et al. (1998) and Shanmugam et al. (2008).

reflectances $\left(R_{r s}\left(\lambda_{3}\right) / R_{r s}\left(\lambda_{2}\right)\right.$, where $\lambda_{3}=665 \mathrm{~nm}$ or $670 \mathrm{~nm}$ and $\lambda_{2}=490$ or $565 \mathrm{~nm}$ ). It seems that the power-law relationship using the ratio of reflectance or radiance at two visible wavelengths (blue-green) is reasonable to provide reliable estimates of $a_{\mathrm{CDOM}}(\lambda)$ from remotely sensed data.

The spectral behavior of the absorption of light by CDOM can be modeled as a function of $\lambda$ using a single exponential model which takes the form as below,

$a_{\mathrm{CDOM}}(\lambda)=a_{\mathrm{CDOM}}\left(\lambda_{R}\right) e^{-S\left(\lambda-\lambda_{R}\right)}$,

where $a_{\mathrm{CDOM}}(\lambda)$ and $a_{\mathrm{CDOM}}\left(\lambda_{R}\right)$ are the absorption coefficients at a certain wavelength $\lambda$ and a reference wavelength $\lambda_{R}$, respectively. $S$ is the spectral slope coefficient (in $\mathrm{nm}^{-1}$ ) that determines the shape of the absorption curve (Jerlov, 1968; Bricaud et al., 1981; Stedmon and Markager, 2001). Although several authors find the slope values to typically vary between 0.01 and 0.02 in their specific data sets, Twardowski et al. (2004) have shown that large differences (perhaps the result of methodological differences) exist in the spectral slope values with much broader ranges inferred with different fitting methods in different water types. This also suggests a high degree of variability in the composition of CDOM in these waters. Under these circumstances, an average $S$ value chosen for remote sensing bio-optical models (e.g. Carder et al., 1999; Kahru and Mitchell, 2001; Binding and Bowers, 2003) may be invalidated when a wide range of 
Table 1. Information regarding the in-situ data. $N$ - number of observations, and SL - salinity.

\begin{tabular}{|c|c|c|c|}
\hline Observation area & Parameters observed & $N$ & Date \\
\hline Jin-hae Bay \& its surrounding areas (KSS east) & $R_{r s}, \mathrm{Chl}, \mathrm{SS}, a_{\mathrm{CDOM}}, a_{p}, a_{s s}$ & 16 & 26-28 Aug 1998 \\
\hline Geoje Island \& Jeju Strait (KSS west) & $R_{r s}, \mathrm{Chl}, \mathrm{SS}, a_{\mathrm{CDOM}}, a_{p}, a_{s s}$ & 4 & 23-26 Sep 1998 \\
\hline Jindo and Wando waters (KSS west) & $R_{r s}, \mathrm{Chl}, \mathrm{SS}, a_{\mathrm{CDOM}}, a_{p}, a_{s s}$ & 53 & 20-23 Oct 1998 \\
\hline Southern area of Yellow Sea & $R_{r s}, \mathrm{Chl}, \mathrm{SS}, a_{\mathrm{CDOM}}, a_{p}, a_{s s}$ & 10 & 1-5 Feb 2001 \\
\hline Yellow Sea & $R_{r s}, \mathrm{Chl}, \mathrm{SS}, a_{\mathrm{CDOM}}, a_{p}, a_{s s}$ & 11 & 4-15 Jun 2001 \\
\hline Jin-hae Bay \& its surrounding areas (KSS east) & $R_{r s}, \mathrm{Chl}, \mathrm{SS}, a_{\mathrm{CDOM}}, a_{p}, a_{s s}$ & 30 & 28-31 Aug 2001 \\
\hline East China Sea & $R_{r s}, \mathrm{Chl}, \mathrm{SS}, a_{\mathrm{CDOM}}, a_{p}, a_{s s}, \mathrm{SL}$ & $5,3(\mathrm{SL})$ & 19-25 Feb 2002 \\
\hline Southern area of Yellow Sea & $R_{r s}, \mathrm{Chl}, \mathrm{SS}, a_{\mathrm{CDOM}}, a_{p}, a_{s s}$ & 6 & 2-3 May 2002 \\
\hline KSS \& Southwestern area of Jeju (KSS west) & $R_{r s}, \mathrm{Chl}, \mathrm{SS}, a_{\mathrm{CDOM}}, a_{p}, a_{s s}, \mathrm{SL}$ & $20,3(\mathrm{SL})$ & 18-22 Jun 2002 \\
\hline Jin-hae Bay \& its surrounding Geoje Island areas (KSS east) & $R_{r s}, \mathrm{Chl}, \mathrm{SS}, a_{\mathrm{CDOM}}, a_{p}, a_{s s}$ & 25 & 2-7 Sep 2002 \\
\hline Southern area of Yellow Sea & $R_{r s}, \mathrm{Chl}, \mathrm{SS}, a_{\mathrm{CDOM}}, a_{p}, a_{s s}$ & 11 & 9-18 Feb 2003 \\
\hline Jin-hae Bay \& its surrounding areas (KSS east) & $R_{r s}, \mathrm{Chl}, \mathrm{SS}, a_{\mathrm{CDOM}}, a_{p}, a_{s s}$ & 16 & 5-6 Aug 2003 \\
\hline Southwestern area of Jeju Island \& East China Sea & $R_{r s}, \mathrm{Chl}, \mathrm{SS}, a_{\mathrm{CDOM}}, a_{p}, a_{s s}, \mathrm{SL}$ & $10,7(\mathrm{SL})$ & $8-10$ Oct 2003 \\
\hline Southwestern area of Jeju Island \& East China Sea & $R_{r s}, \mathrm{Chl}, \mathrm{SS}, a_{\mathrm{CDOM}}, a_{p}, a_{s s}, \mathrm{SL}$ & $10,4(\mathrm{SL})$ & 23-25 Mar 2004 \\
\hline Southern area of Yellow Sea & $R_{r s}, \mathrm{Chl}, \mathrm{SS}, a_{\mathrm{CDOM}}, a_{p}, a_{s s}$ & 11 & 9-12 May 2004 \\
\hline Jin-hae Bay \& its surrounding Geoje Island areas (KSS east) & $R_{r s}, \mathrm{Chl}, \mathrm{SS}, a_{\mathrm{CDOM}}, a_{p}, a_{s s}$ & 8 & 10-11 Aug 2004 \\
\hline Southwestern area of Jeju Island \& East China Sea & $R_{r s}, \mathrm{Chl}, \mathrm{SS}, a_{\mathrm{CDOM}}, a_{p}, a_{s s}, \mathrm{SL}$ & 1 & 26-27 Mar 2005 \\
\hline Southern area of Yellow Sea & $R_{r s}, \mathrm{Chl}, \mathrm{SS}, a_{\mathrm{CDOM}}, a_{p}, a_{s s}$ & 7 & 29 May 2005 \\
\hline East China Sea & $R_{r s}, \mathrm{Chl}, \mathrm{SS}, a_{\mathrm{CDOM}}, a_{p}, a_{s s}, \mathrm{SL}$ & 6 & 22-29 Aug 2005 \\
\hline
\end{tabular}

water types is considered of interest. Thus, we introduce a method that permits the use of the fixed wavelength ratio of $a_{\mathrm{CDOM}}(400)$ and $a_{\mathrm{CDOM}}(412)$ for estimating $S$ and therefore simplifies the comparison of $S$ values from CDOM in different environments. The method takes the form

$S=\left(\frac{1}{\lambda_{i}-\lambda_{j}}\right) \times \ln \left(\frac{a_{\mathrm{CDOM}}\left(\lambda_{i}\right)}{a_{\mathrm{CDOM}}\left(\lambda_{j}\right)}\right)$,

where $\lambda_{i}$ and $\lambda_{j}$ are $412 \mathrm{~nm}$ and $400 \mathrm{~nm}$ and now the above equation becomes

$$
\begin{aligned}
S & =\left(\frac{1}{12}\right) \times \ln \left(\frac{a_{\mathrm{CDOM}}(412)}{a_{\mathrm{CDOM}}(400)}\right) \\
& =\left(\frac{1}{12}\right) \times \ln \left(\frac{\alpha\left(R_{r s}\left(\lambda_{1}\right) / R_{r s}\left(\lambda_{2}\right)\right)^{-\beta}}{\alpha\left(R_{r s}\left(\lambda_{1}\right) / R_{r s}\left(\lambda_{2}\right)\right)^{-\beta}}\right),
\end{aligned}
$$

where $\alpha$ and $\beta$ are the regression coefficients for estimating $a_{\mathrm{CDOM}}(400)$ and $a_{\mathrm{CDOM}}(412)$ using the reflectance band ratio algorithms. This calculation allows a better estimation of $\mathrm{S}$ to distinguish between marine and terrestrial organic matter from measurements of the absorption at two of these wavelengths.

\section{Materials and methods}

\subsection{Data sets and measurements}

Data used in this study were collected from a wide range of water types in the ECS, YS and KSS. Table 1 provides the information on the time and location, and type and number of measurements, all made within sampling grids illustrated on the regional map in Fig. 1. For each station, remote sensing reflectance $\left(R_{r s}\right)$, chlorophyll $(\mathrm{Chl})$, suspended sediment (SS), and absorption coefficients of CDOM $\left(a_{\mathrm{CDOM}}\right)$, phytoplankton $\left(a_{p}\right)$ and non-algal particles $\left(a_{s s}\right)$ of water samples were measured. There were fewer salinity (SL) measurements but taken mostly from the YR estuarine, mixing and oceanic regions of the ECS. In what follows the methods of these measurements relevant to this study are briefly described.

\subsection{Remote sensing reflectance $\left(\mathrm{R}_{r s}\right)$}

For each cruise and at each station, in-situ radiometric measurements (above the seawater) were performed in the 350$1050 \mathrm{~nm}$ spectral range (with a $1.4 \mathrm{~nm}$ spectral interval) from a calibrated ASD FieldSpec Pro Dual VNIR Spectroradiometer. These measurements included the total water leaving radiance $t L_{w}(\lambda)$, sky radiance $L_{\text {sky }}(\lambda)$ and downwelling irradiance $E_{d}(\lambda)$. The $t L_{w}(\lambda)$ and $L_{\text {sky }}(\lambda)$ were measured with a pointing angle $\theta \sim 25-30^{\circ}$ from nadir and an azimuthal angle $\phi \sim 90^{\circ}$ from the solar plane, whereas sky radiance was measured in the same plane as $t L_{w}(\lambda)$ but from a direction of $\theta \sim 30$ from zenith. $E_{d}(\lambda)$ was measured by pointing the sensor upward from the deck. Most of these measurements were made in excellent conditions, near solar noon and under almost cloudless conditions. Since $t L_{w}(\lambda)$ consisted of the desired water-leaving radiance $L_{w}(\lambda)$ and a contamination term $\Delta L\left(=F_{r}(\lambda) \times L_{\text {sky }}(\lambda)\right)$, it was necessary to correct the recorded data $\left(\mathrm{mW} \mathrm{cm}^{-2} \mu \mathrm{m}^{-1} \mathrm{sr}^{-1}\right)$ for these 
contributions of skylight reflection $\left(L_{\text {sky }}(\lambda)\right)$ and Fresnel reflectance $\left(F_{r}(\lambda)\right)$ of air-sea interface using,

$L_{w}(\lambda)=t L_{w}(\lambda)-\Delta L$.

In the above calculation, the values of $L_{\text {sky }}(\lambda)$ were obtained from the sky radiometer, and the $F_{r}$ value was assumed to be 0.025 (Austin, 1974). In fact, $F_{r}$ varies with viewing geometry, sky conditions and sea surface roughness due to wind and is wavelength-dependent under a cloudy sky (Mobley, 1999). Applying these values in Eq. (5) yielded the water-leaving radiance $\left(L_{w}(\lambda)\right)$, which was then divided by downwelling irradiance to obtain the remote sensing reflectance $R_{r s}(\lambda)$ using,

$R_{r s}\left(0^{+} \lambda\right)=\frac{L_{w}(\lambda)}{E_{d}\left(0^{+} \lambda\right)}$,

where the $R_{r s}(\lambda)$, referred in units of $\mathrm{sr}^{-1}$, is an apparent optical property (AOP) that contains the spectral information of the water-leaving radiance, but which is largely free of its magnitude variability. Thus, algorithms and models have been developed to relate $R_{r s}$ measurements to in-water constituents, such as Chl, SS and CDOM (e.g. O.Reilly et al., 1998; He et al., 2000; Montes-Hugo et al., 2005; Johannessen et al., 2003).

\subsection{Absorption coefficient of CDOM}

Immediately after collection with Niskin bottles, the samples were filtered on board through $0.45 \mu \mathrm{m}$ membrane syringe filters $(25 \mathrm{~mm})$, previously rinsed with ultra pure Milli$\mathrm{Q}$ water and $50 \mathrm{ml}$ of the sample were stored in glass flasks in the dark at $4^{\circ} \mathrm{C}$ for analysis in laboratory. After returning to the laboratory, the absorbance of CDOM was measured between 350-900 nm (with $1 \mathrm{~nm}$ increments) using a dual-beam Perkin-Elmer Lambda 19 spectrophotometer. The measurements were performed by placing a $10 \mathrm{~cm}$ quartz cuvette containing Milli-Q water in the optical path of the reference beam, and a $10 \mathrm{~cm}$ quartz cuvette containing the filtered seawater sample in the optical path of the sample beam. The spectral absorption coefficient $a_{\mathrm{CDOM}}(\lambda)$ was computed from the measured absorbance resulting from the difference between the sample absorbance and the reference absorbance (Ferrari et al., 1996), from

$a_{\mathrm{CDOM}}(\lambda)=\frac{2.3025 \times A_{\mathrm{CDOM}}(\lambda)}{L c}$,

where $L c$ is the path length of the cuvette (i.e. 0.1 in units of meters). The $a_{\mathrm{CDOM}}(\lambda)$ values measured for a variety of water types were generally found to decrease almost exponentially throughout the near UV and visible spectral domains (Bricaud et al., 1981; D'Sa et al., 1999).

\subsection{Salinity}

Salinity measurements data were collected from the conductivity-temperature-depth (CTD) sensors (Sea-Bird
Electronics) during the six R/V EARDO cruises (2002$2005)$ in the ECS, southern YS and western Jeju Island. Another set of salinity data along with the $a_{\mathrm{CDOM}}(400)\left(\mathrm{m}^{-1}\right)$ measured with a Lambda-18 spectrophotometer from Miller et al. (2002), were also included in our analysis to find an appropriate relationship with higher accuracy and apply it to a variety of waters. They collected these data for a wide range of waters in the Bay St. Louis, MS, Lake Pontchartrain, LA, Mississippi Sound, MS, and Mississippi River Delta, MS. The above data sets are a good representative of the rivers, coastal, estuarine, mixing and oceanic regions, and are therefore used to derive an algorithm for retrieving salinity, which is a primary tracer of the LSW plume around coast and estuary.

\subsection{Satellite data and processing}

Siegel et al. (2002), D'Sa et al. (2002) and Johannessen et al. (2003) have demonstrated that ocean colour data from NASA's (National Aeronautics and Space Administration) SeaWiFS sensor can be used to derive the products of $a_{\mathrm{CDOM}}$ and salinity for regional-global waters. Thus, full resolution ( $\sim 1 \mathrm{~km} /$ pixel at nadir) Level 1A SeaWiFS ocean colour radiances for eight narrow spectral channels in the visible and near-infrared spectral domains were collected from the KORDI-HRPT station over the periods April-May 19982005 that coincided with the development of the LSW plume in the ECS. The selection of these data - one for each year representing the springtime variability of CDOM and salinity in the ECS - was based on our previous analysis of the YR plume that develops in large areal coverage during the springtime (Ahn et al., 2004). All Level 1A SeaWiFS data were carefully scrutinized and only those useful for analysis were selected by investigating the LSW plume situations using visual/digital methods and by discarding the scenes severely contaminated by clouds/extreme atmospheric conditions. The digital radiance counts of Level 1A SeaWiFS raw data were converted to total radiance $\left(\mathrm{mW} \mathrm{cm}-2 \mu \mathrm{m}^{-1} \mathrm{sr}^{-1}\right.$ ) at the level of the top-of-atmosphere (TOA) by employing the SeaWiFS band sensitivity and pre-launch calibration coefficients given in NASA's SeaWiFS technical report series (Hooker et al., 1994). Because the strongly absorbing aerosols and high turbid water column with significant amounts of CDOM $\left(>0.5 \mathrm{~m}^{-1}\right)$ and SS $\left(>10 \mathrm{~g} \mathrm{~m}^{-3}\right)$ during April-May affected the performance of the standard atmospheric correction (SAC) scheme, we used the spectral shape matching method ("SSMM", Ahn and Shanmugam, 2004; Shanmugam and Ahn, 2007) for atmospheric correction of SeaWiFS data and retrieved the desired waterleaving radiances $\left(L_{w}(\lambda)\right.$. The atmospherically corrected $L_{w}(\lambda)$ values were subsequently converted to reflectance using $\rho=\pi L_{w} / F_{o} \cos \theta_{o}$ (where $F_{o}$ and $\theta_{o}$ are the mean extraterrestrial solar irradiance and solar zenith angle, respectively) and then divided by $\pi$ steradians to compare to the remote-sensing reflectance: $1 / \pi \rho(\lambda) \approx R_{r s}(\lambda)$. 

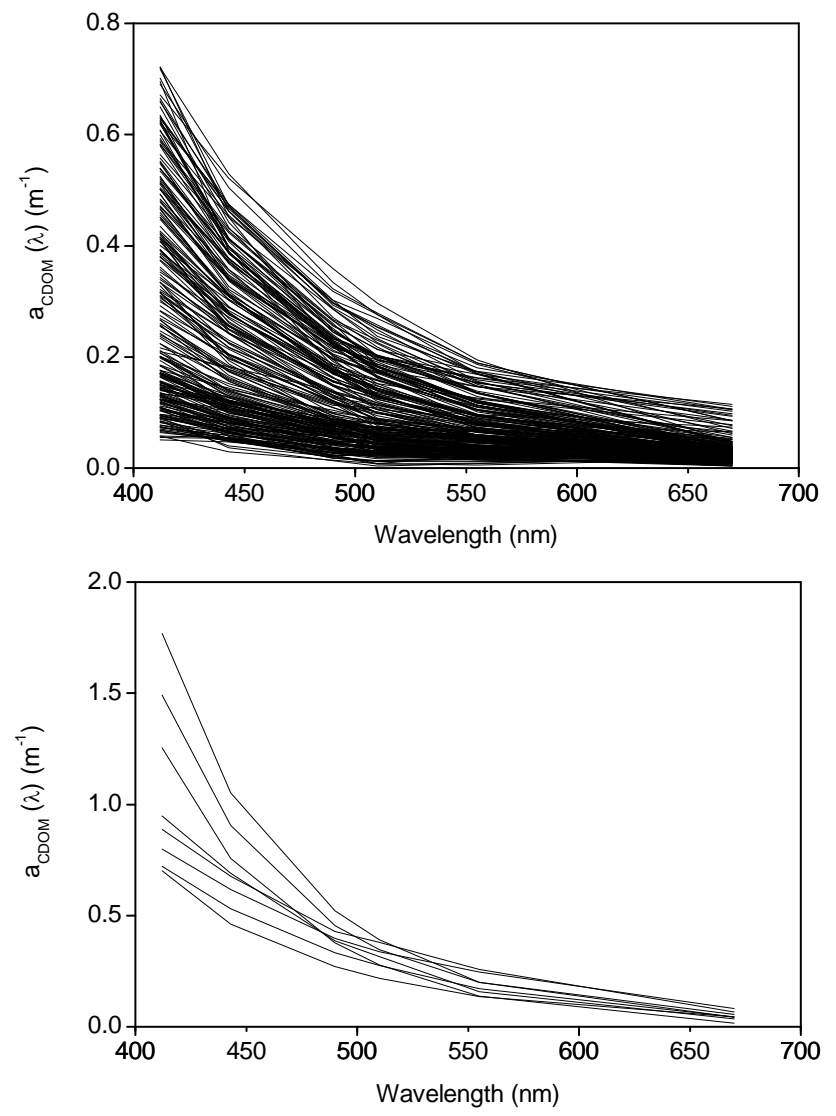

Fig. 2. Spectral variations in the absorption coefficient of coloured dissolved organic matter $\left.\left(a_{\mathrm{CDOM}}(\lambda), \mathrm{m}^{-1}\right)\right)$ in ECS, YS and KSS waters $(N=470)$. Top panel is from the ECS, YS and also KSS and bottom panel is from the KSS.

For comparison, we also processed some of SeaWiFS images using the SAC algorithm (with SeaDAS version 4.4) and estimated $a_{\mathrm{CDOM}}$ and salinity using the empirical relationships developed in this study.

\section{Results}

\subsection{Spectral variations of CDOM}

Spectral variations of the absorption coefficient of CDOM $\left(a_{\mathrm{CDOM}}(\lambda)\right)$ are shown in Fig. 2 . The general spectral curves show very low absorption values $\left(<0.163 \mathrm{~m}^{-1}\right)$ at the red portion of the visible spectrum $(650 \mathrm{~nm})$, which increase to maximum values according to exponential laws in the near UV/lower blue domains $(400-412 \mathrm{~nm})$, as previously reported by Bricaud et al. (1981). $a_{\mathrm{CDOM}}$ (412) values were generally observed to range from $0.05-0.6 \mathrm{~m}^{-1}$ in the ECS and YS characterized by $\mathrm{Chl} 0.4-7.9 \mathrm{mg} \mathrm{m}^{-3}$ and SS $0.5-$ $68 \mathrm{~g} \mathrm{~m}^{-3}$, and from $0.9-1.76 \mathrm{~m}^{-1}$ in the KSS characterized by Chl $0.08-119 \mathrm{mg} \mathrm{m}^{-3}$ and SS $1.4-260 \mathrm{~g} \mathrm{~m}^{-3}$. The values higher than $0.9 \mathrm{~m}^{-1}$ in the KSS coastal areas may be re- lated to increased contamination/pollution of waters (bottom panel), and the values lower than $0.3 \mathrm{~m}^{-1}$ in offshore waters of the ECS and YS may be the result of the freshwater influence and local biological activity near the surface layer (top panel). The CDOM measured in the ECS (southwest off Jeju Island) are generally at moderate levels $\left(0.3-0.6 \mathrm{~m}^{-1}\right)$, largely influenced by high fluvial discharges at the mouth of the YR and advection processes at the offshore areas of the YR mouth. Higher magnitudes are often evident toward the ECS coast, particularly during the peak-runoff periods from late spring-summer (Guo et al., 2007; Tang, 2008).

\subsection{Estimating $a_{\mathrm{CDOM}}(400,412)$ from remote sensing re- flectance $\left(R_{r s}\right)$}

To estimate CDOM absorptions at these two wavelengths, we tried to find the strongest relationship between logtransformed $a_{\mathrm{CDOM}}(400,412)$ and log-transformed three spectral ratios of the remote sensing reflectance $R_{r s}$ (412)/ $R_{r s}$ (555), $R_{r s}$ (443)/R $R_{r s}$ (555) and $R_{r s}$ (490)/ $R_{r s}$ (555) from our large in-situ bio-optical data set collected in the study regions (Fig. 3 with inclusion of regression coefficients). The basic thought behind selecting and examining these band combinations and ratios is that variations in $R_{r s}$ at the blue wavelengths are strongly affected by CDOM absorption, compared with other light absorbing water constituents, and variations in $R_{r s}$ at the green wavelengths are the most affected by light scattering by particles (Johannessen et al., 2003; Belanger et al., 2008). Of the three ratios examined, the ratio of reflectance at $412 \mathrm{~nm}$ to reflectance at $555 \mathrm{~nm}$ allowed one to predict $a_{\mathrm{CDOM}}(400)$ and $a_{\mathrm{CDOM}}$ (412) more robustly with the correlation coefficient $R^{2}=0.67$. As CDOM absorption had a characteristic exponential decay with wavelength, it was not well correlated with the $R_{r s}$ (443)/ $R_{r s}$ (555) and $R_{r s}(490) / R_{r s}$ (555) ratios, and thus the relationships between these ratios and $a_{\mathrm{CDOM}}$ at 400 and $412 \mathrm{~nm}$ were weakly consistent $\left(R^{2}=0.53-0.54\right.$ for $R_{r s}$ $(443) / R_{r s}(555)$ vs. $a_{\mathrm{CDOM}}(400,412)$, and $R^{2}=0.39-0.40$ for $R_{r s}(490) / R_{r s}(555)$ vs. $a_{\mathrm{CDOM}}(400,412)$, for $\left.N=254\right)$. Statistical regression analysis of the former relationships provided the best-fit power function equations with constant coefficients (Fig. 3) that capture a large fraction of the variation in the reflectance band ratios $\left(R_{r s}(412) / R_{r s}(555)\right)$ and variation in the $a_{\mathrm{CDOM}}$ values (at 400 and $412 \mathrm{~nm}$ ). However, this was not the case for the later power models (of $R_{r s}$ $(443) / R_{r s}$ (555) and $R_{r s}(490) / R_{r s}$ (555) vs. $a_{\mathrm{CDOM}}(400$, 412)) that did not linearly fit the most frequent central and extreme data. This suggests that a wide range of variability in $a_{\mathrm{CDOM}}$ is difficult to retrieve from these relationships. Thus, this study fixes the $R_{r s}(412) / R_{r s}$ (555) ratio as a predictor of the $a_{\mathrm{CDOM}}$ at $400 \mathrm{~nm}$ and $412 \mathrm{~nm}$. If the atmospheric correction of blue band is accurate, then the estimation of $a_{\mathrm{CDOM}}$ would be easily achieved from satellite ocean colour observations and could be used to study its variability in a wide range of water types encountered in the ECS region. 

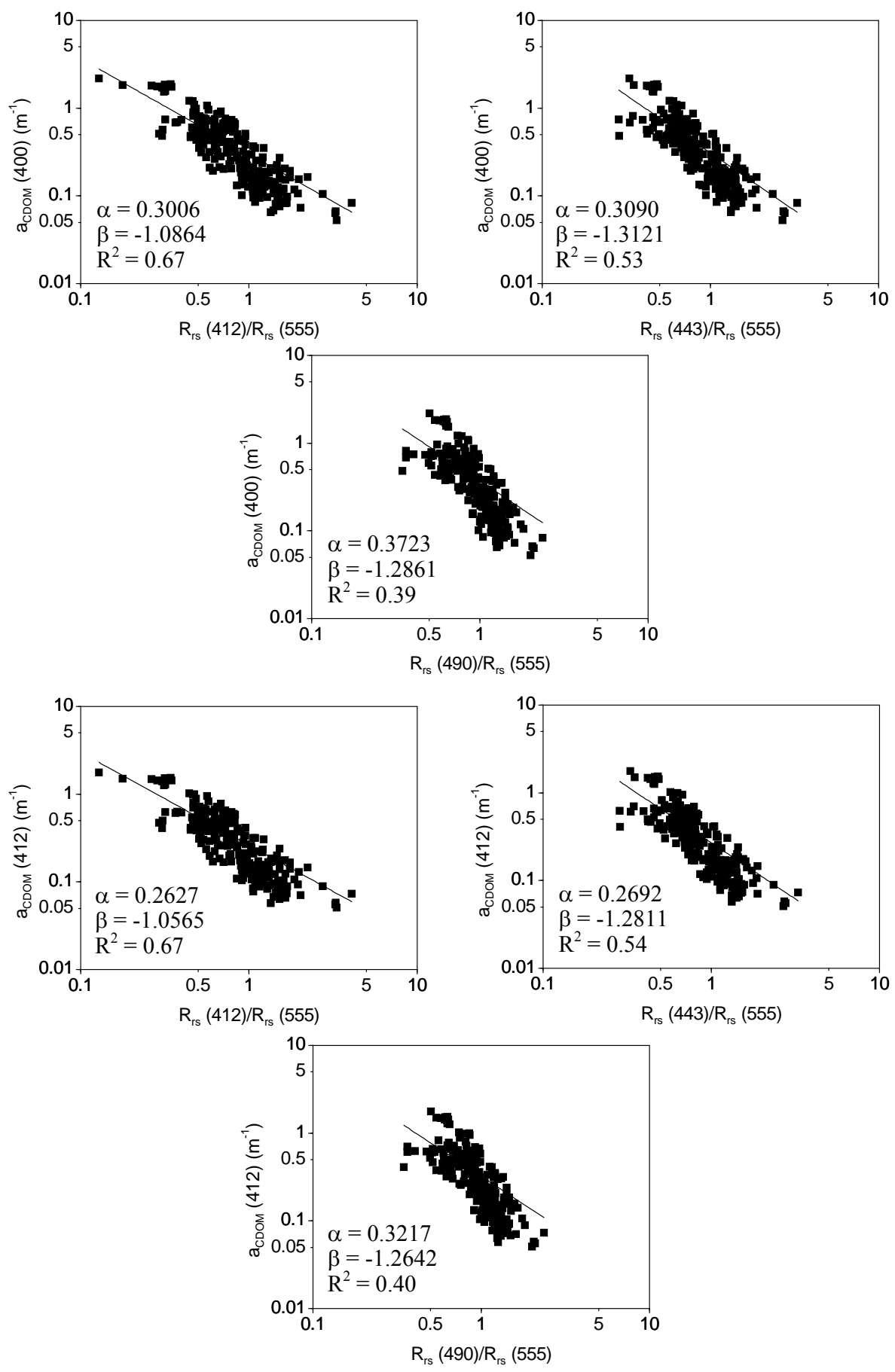

Fig. 3. Relationships between the three $R_{r s}$ ratios and $a_{\mathrm{CDOM}}(400,412)\left(\mathrm{m}^{-1}\right)$ measured (in-situ) in a wide range of waters from the ECS, YS and KSS during 1998-2005 $(N=254)$.

\subsection{Relationship between salinity and $a_{\mathrm{CDOM}}(\lambda)$}

As the salinity has no direct colour signal, it could be rather estimated through the colour signal dominated by major water constituents, such as the CDOM (Moon et al., 2006; Del Castillo and Miller, 2008). Thus, this study was to exam- ine the relationships between salinity and absorption coefficient of CDOM measured in estuarine and offshore waters of the ECS. Figure 4 displays the scatter plots of salinity versus $a_{\mathrm{CDOM}}$ at $400 \mathrm{~nm}, 412 \mathrm{~nm} 443 \mathrm{~nm}$ and $490 \mathrm{~nm}\left(\mathrm{~m}^{-1}\right)$, wherein tight, inverse relationships of salinity and $a_{\mathrm{CDOM}}(\lambda)$ were observed with high correlation coefficients $\left(R^{2}>0.66\right)$ 

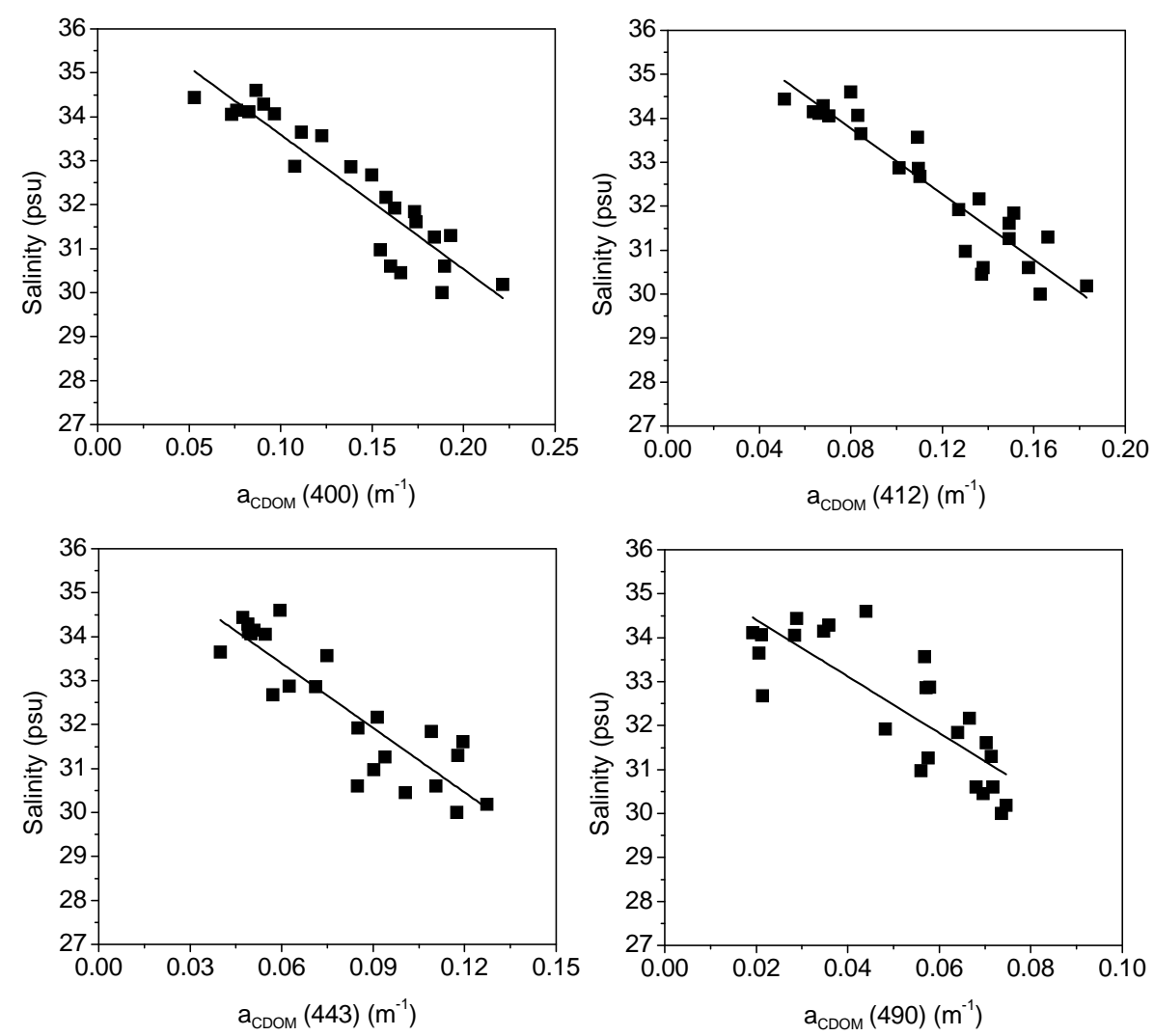

Fig. 4. Relationships between the salinity and $a_{\mathrm{CDOM}}(\lambda)\left(\mathrm{m}^{-1}\right)$ observed in estuarine and offshore waters of the ECS during $2002-2005$ $(N=24)$.

Table 2. Parameters for the estimation of salinity (psu) from the $a_{\mathrm{CDOM}}(\lambda)$.

\begin{tabular}{cccccc}
\hline Algorithms & $a_{\text {CDOM }}(\lambda)$ & $A$ & $B$ & $R^{2}$ & $N$ \\
\hline Salinity & $a_{\text {CDOM }}(400)$ & -30.6416 & 36.6551 & 0.86 & 24 \\
Salinity & $a_{\text {CDOM }}(412)$ & -37.3089 & 36.7550 & 0.85 & 24 \\
Salinity & $a_{\text {CDOM }}(443)$ & -48.9630 & 36.3301 & 0.77 & 24 \\
Salinity & $a_{\text {CDOM }}(490)$ & -64.4025 & 35.6943 & 0.66 & 24 \\
Salinity & $a_{\text {CDOM }}(400)$ & 35.064 & -0.3357 & 0.98 & 37 \\
\hline
\end{tabular}

that decreased from $0.86-0.66$ with CDOM absorption at the increased wavelengths. Linear regression of the salinity performed against $a_{\mathrm{CDOM}}(\lambda)$ data was found quite appropriate for this data, yielding approximately the following expression,

Salinity (psu) $=A \times a_{\mathrm{CDOM}}(\lambda)+B$,

where $A$ and $B$ are the regression coefficients given in Table 2. As a consequence of its fresh water origin and conservative behavior, CDOM absorption in coastal seas has been previously observed to be inversely correlated with salinity in the same way, and therefore has been considered a good indicator of salinity in various regions (e.g. Jerlov, 1968; Nelson and Guarda, 1995; Boss et al., 2001; Binding and Bowers, 2003; Kwalczuk et al., 2005; Moon et al., 2006; Guo et al., 2007; Sasaki et al., 2008). Findings from the above relationships of salinity and $a_{\mathrm{CDOM}}(\lambda)$ revealed that salinity seemed to be better correlated with $a_{\mathrm{CDOM}}$ at $400 \mathrm{~nm}$ than $a_{\mathrm{CDOM}}$ at other longer wavelengths, and therefore $a_{\mathrm{CDOM}}$ at $400 \mathrm{~nm}$ could be used as a proxy for salinity in this region.

Since our data were determined by the ranges of 30-34.4 (psu) salinity and $0.05-0.22\left(\mathrm{~m}^{-1}\right) a_{\mathrm{CDOM}}$ (400), it was quite difficult to find a more appropriate relationship between salinity and $a_{\mathrm{CDOM}}(400)$ and apply it to satellite data to infer salinity in a variety of water types commonly observed in the riverine-estuarine systems. By adding the data of Miller et al. (2002), we found that the salinity was highly inversely correlated $\left(R^{2}=0.98\right)$ with $a_{\mathrm{CDOM}}(400)$, with a substantial positive intercept, and this correlation corresponded best with an exponential rather than a linear function of $a_{\mathrm{CDOM}}$ (400) measured in waters of the ECS (Fig. 5). The best-fit exponential curve (with the smallest error of slope, 0.03) for a variety of samples can be approximated by

$$
A \times e^{\left(B \times a_{\mathrm{CDOM}}(400)\right)},
$$


with the more reliable regression coefficients described in Table 2. It was noted that the variability in CDOM concentration within waters of low salinity 2.5-12 psu (when considering all data from Miller et al., 2002) was slightly larger than that found in waters of high salinity 30-34.4 psu (ECS). This may be due to the higher CDOM concentration/variability in riverine inputs and accumulation of CDOM from in-water productivity and/or sediment-released CDOM into the regions studied by Miller et al. (2002). This trend of variability in waters of high CDOM concentration and low salinity has been reported in several earlier investigations of similar environments (Vodacek et al., 1997; Boss et al., 2001; Twardowski and Donaghay, 2001; Guo et al., 2007). Binding and Bowers (2003) pointed out that a part of such variability may also occur both geographically and temporally with factors such as variations in the availability and type of organic matter, volume and persistence of rainfall, and size of catchment area. However, the existence of the tight, inverse relationship between salinity and $a_{\mathrm{CDOM}}(400)$ for a variety of samples from different seasons and from a variety of water types, implies that the salinity variation around the mouth and estuary of the YR can be accurately estimated if products of the CDOM absorption are assured by the atmospheric correction scheme applied to satellite data.

\subsection{Validation of $a_{\mathrm{CDOM}}(400)$ and salinity retrievals}

We applied the respective relationships (in Figs. 3 and 5, Table 2) to our in-situ $R_{r s}$ data (from spring-summer 20022005 ) and compared the model estimates of $a_{\mathrm{CDOM}}$ (400) $\left(\mathrm{m}^{-1}\right)$ and salinity (psu) with those from shipboard measurements obtained in estuarine mixing and oceanic waters of the ECS (Fig. 6). Although the data set used for this validation contains only 13 in-situ measurements, it provides a better idea about the overall performance of these models for estimating $a_{\mathrm{CDOM}}(400)$ and salinity in the LSW plume region of the ECS. It appears that the $a_{\mathrm{CDOM}}(400)$ values are closely linearly aligned around the 1:1 line, although slightly higher than the in-situ $a_{\text {CDOM }}$ (400) values. The overestimation is particularly more pronounced for highly turbid waters with $a_{\mathrm{CDOM}}(400)>0.5 \mathrm{~m}^{-1}$ and less pronounced for relatively clear waters with $a_{\mathrm{CDOM}}(400)<0.1 \mathrm{~m}^{-1}$. However, LSW plume contains $a_{\mathrm{CDOM}}$ (400) values typically ranging from $0.08-0.4 \mathrm{~m}^{-1}$ toward the ECS coast and $0.05-0.25 \mathrm{~m}^{-1}$ toward the estuarine mixing waters offshore of the mouth of the YR (Moon et al., 2007; Tang, 2008). As a result, the model performance is found to be quite satisfactory with the mean relative error MRE 0.58 (= model $a_{\mathrm{CDOM}}(400)-$ insitu $a_{\mathrm{CDOM}}(400) /$ in-situ $\left.a_{\mathrm{CDOM}}(400)\right)$ and correlation coefficient $R^{2} 0.71$. On the other hand, the comparison between modeled and measured salinity shows good agreement (MRE $=-0.009, R^{2}=0.41$ ), but with increased scatter of matches underlying the regression line in Fig. 6 (plot on the right side). This suggests slight uncertainty in salinity retrievals which may be associated with errors in model es-

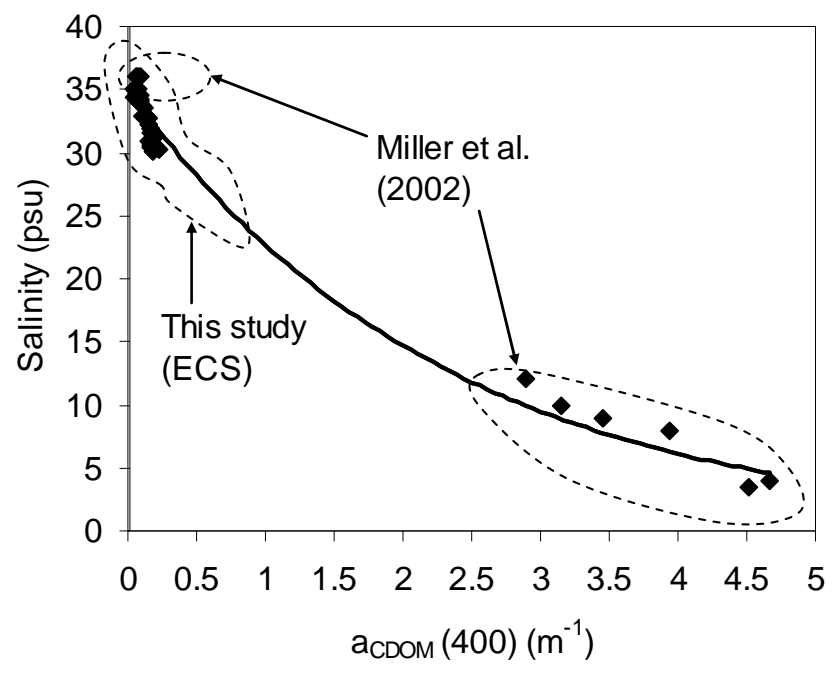

Fig. 5. Relationship between the salinity and $a_{\mathrm{CDOM}}(400)\left(\mathrm{m}^{-1}\right)$ measured in a diverse range of waters from the ECS and other regions $(N=37)$.

timates of the $a_{\mathrm{CDOM}}$ (400) from in-situ $R_{r s}$ data. Nevertheless, the nonlinear exponential relationship would achieve a relatively higher accuracy ( $\pm 1 \mathrm{psu})$ for estimating salinity in comparison with other linear models previously developed for this region (Sasaki et al., 2008).

\subsection{Implementation to SeaWiFS ocean colour imagery}

The relationships obtained in this study were implemented together with the regional atmospheric correction algorithm (SSMM) to a series of SeaWiFS images of the springtime (1998-2005, no reliable cloud free images available for April-May in 2000 and 2002) for mapping and monitoring the LSW plume in the YR estuary and coastal areas of the ECS, where conservative behavior of CDOM during estuarine mixing and $\mathrm{CCC}$ waters has been reported in the previous shipboard or satellite-based observations (Ahn et al., 2004; Guo et al., 2007). Figures 7 and 8 show persistent patches of $a_{\mathrm{CDOM}}$ (400) associated with the LSW plume, coinciding with the broad continental shelf of the $50 \mathrm{~m}$ isobath east of the YR mouth and south/west of the YS. It is interesting to note that $a_{\mathrm{CDOM}}$ (400) is seen to be typically below $0.15 \mathrm{~m}^{-1}$ in Kuroshio waters and varies from $0.15 \mathrm{~m}^{-1}$ in YS/offshore waters to $0.4 \mathrm{~m}^{-1}$ in YRDW waters formed by mixing between the YR runoff and saline waters south/west of the YS. A pronounced CDOM maximum is found within regions of the concentrated fresh water runoff and around the mouth of the YR, where $a_{\mathrm{CDOM}}(400)$ reaches $0.5 \mathrm{~m}^{-1}$. Figure 8 reveals that salinity fields inversely correspond with the above CDOM values: higher salinities ( $>34$ psu) are always present in regions of persistent Kuroshio current which flows along the shelf-break up to the area around $30^{\circ} \mathrm{N}, 129^{\circ} \mathrm{E}$ where it turns northeastward and eastward and then exits the 

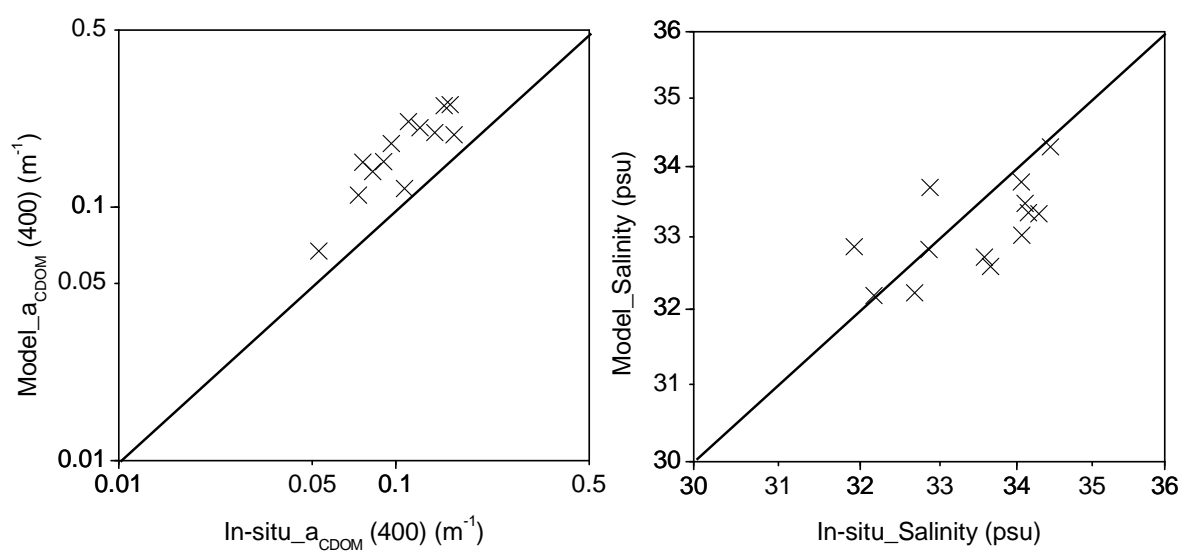

Fig. 6. Comparison of modeled $a_{\mathrm{CDOM}}(400)\left(\mathrm{m}^{-1}\right)$ and salinity (psu) with those from shipboard measurements (in-situ) obtained in the ECS during spring-summer 2002-2005 $(N=13)$.

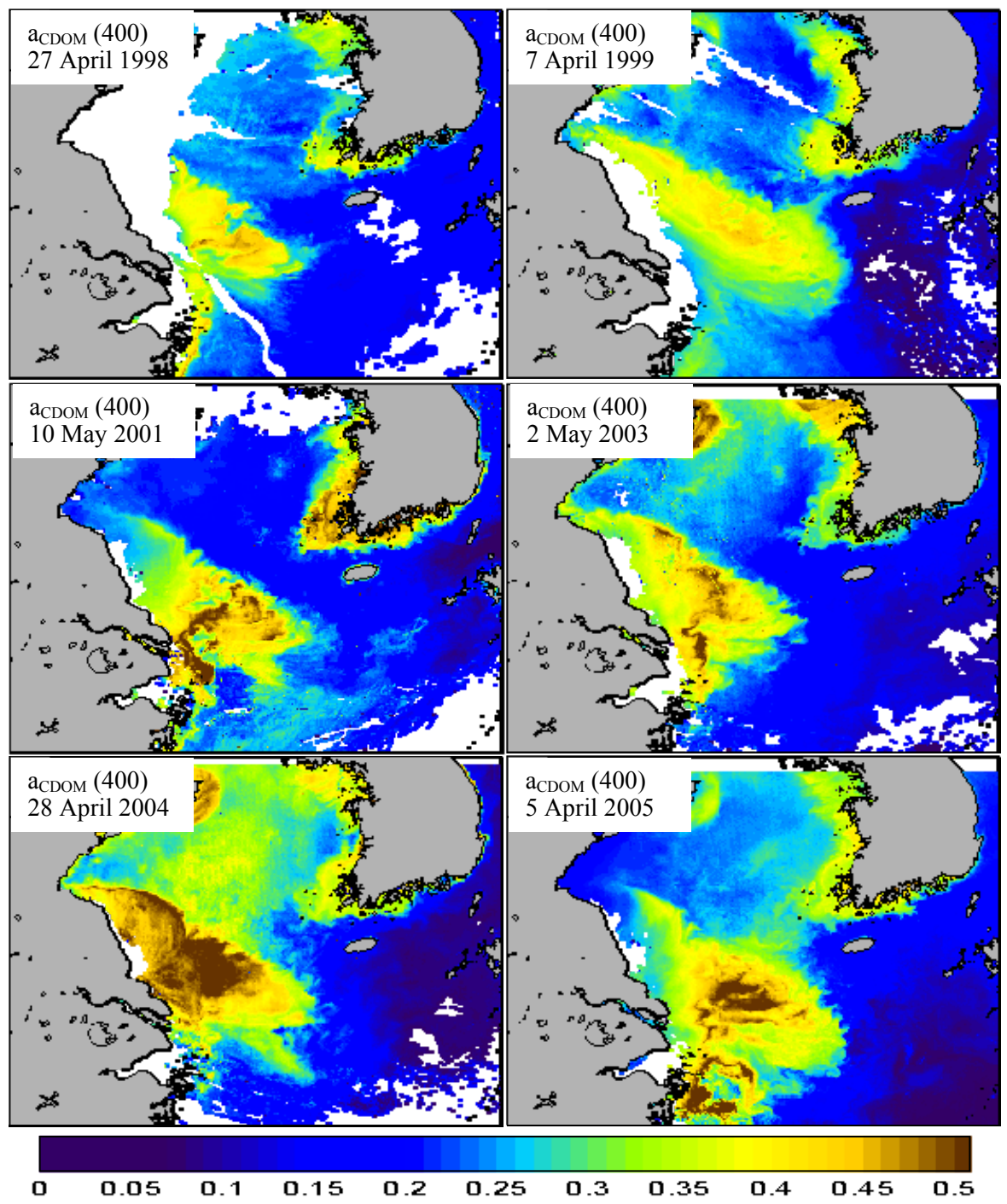

Fig. 7. Maps derived from the SeaWiFS images showing the springtime distribution of coloured dissolved organic matter $\left(a_{\mathrm{CDOM}}\right.$ at $400 \mathrm{~nm}$, $\mathrm{m}^{-1}$ ) in the ECS, YS and KSS. SSMM atmospheric correction was applied to process these images. 


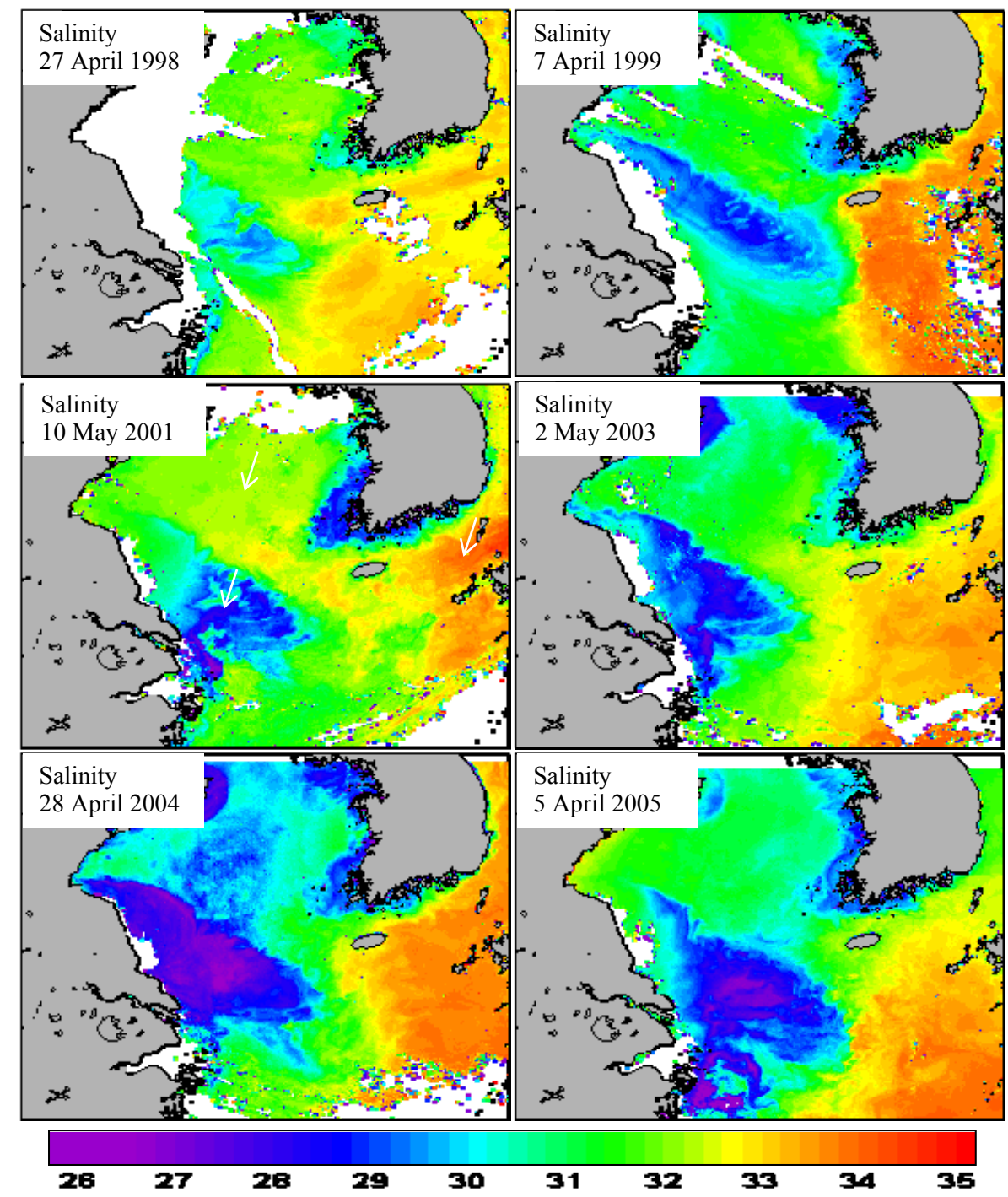

Fig. 8. Maps derived from the SeaWiFS images showing the springtime evolution of salinity fields (psu) in the ECS, YS and KSS. SSMM atmospheric correction was applied to process these images.

ECS through the Tsushima Strait in the northwest and Tokara Strait in the south of Kyushu (Feng et al., 2000); moderate salinities (30-32 psu) are often observed in the YS where these values go up to 34 psu when the Yellow Sea Warm Current (YSWC) as a breach of Kuroshio intrudes into the southern YS northwest off the Jeju Island (Lie and Cho, 2002); minimum salinities are noticed around YRDW (28.5-30 psu) and mouth of the YR (26.5-28.5 psu). SeaWiFS-derived salinity images also reveal the source and extent of these low salinity waters that appear to be displaced north of the YR mouth and adopt a nearly linear pattern corresponding with the broad ECS shelf (7 April 1999 as a good example). These results are closely consistent with previous shipboard observations of the surface salinity in the ECS and modeling studies (Chen at al., 2006, 2008). The contributions of high CDOM concentrations and hence lower salinities are also noted on occasions in the central part of the YS because of the seaward spreading of the LSW plume during the late April-summer (e.g. 28 April 2004).

Once the LSW plume is generated during the springsummer, physical circulation features along with wind fields contribute to the likelihood of the LSW plume being advected into the Kuroshio for transport to the downstream side of Korea and Japan. This is particularly evident in several of the images (Figs. 7 and 8), consistently showing the eastward spreading of the plume over the broad ECS shelf that reaches as far as Jeju Island and the shelf-break, where the Kuroshio flowing northward transports the LSW plume to the northeastern and further eastern areas of the Jeju Island. This not only leads to extensive water exchange between the ECS and Kuroshio across the shelf-break, but also strongly influences the optical properties of these waters during the 

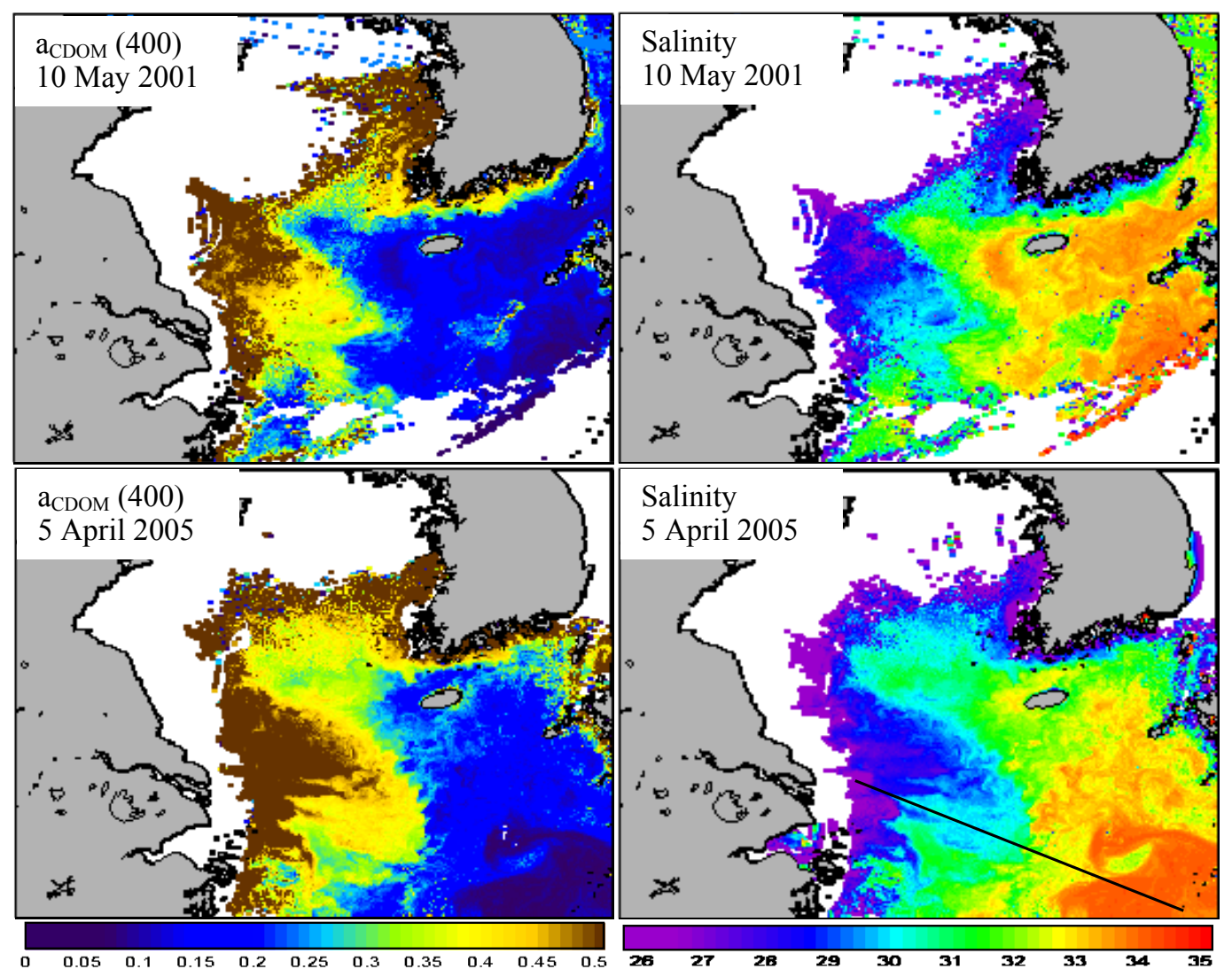

Fig. 9. SeaWiFS images of coloured dissolved organic matter $\left(a_{\mathrm{CDOM}}\right.$ at $\left.400 \mathrm{~nm}\left(\mathrm{~m}^{-1}\right)\right)$ and salinity (psu) for $10 \mathrm{May} 2001$ and 5 April 2005. Standard atmospheric correction (SAC) was applied to process these images.

spring-summer season. The 10 May 2001 image is a good example to show how the YR greatly influences the colour of the ECS where high $a_{\mathrm{CDOM}}(400)\left(0.5 \mathrm{~m}^{-1}\right)$ abundances emerging from the southern channel of the YR appear to move northward, then eastward and finally spread out to the shelf area with varying salinities $27-30$ psu. This pattern may be influenced by the TaWC which flows northward steadily in this period, carrying water with deep ocean and coastal properties originating from the Kuroshio branching and Taiwan Strait (elevated CDOM concentrations, $0.25-0.3 \mathrm{~m}^{-1}$, in the 10 May 2001 image).

To assess how reliable these products are when using the standard atmospheric correction (SAC) algorithm for operational mapping and monitoring of the LSW plume in the ECS, two of the above SeaWiFS images acquired on 10 May 2001 and 5 April 2005 were processed using the SAC algorithm and estimates of $a_{\mathrm{CDOM}}(400)\left(\mathrm{m}^{-1}\right)$ and salinity (psu) were obtained using the same relationships applied before (Fig. 9). Although the SAC algorithm tended to produce realistic estimates of $a_{\mathrm{CDOM}}(400)$ and salinity in the Kuroshio Current region (offshore), it showed large errors $\left(a_{\mathrm{CDOM}}\right.$ at $400>10 \mathrm{~m}^{-1}$, and salinity $<10 \mathrm{psu}$ ) around the edges of clouds/aerosols and masked out the entire nearshore areas.
This resulted in the reduced areal coverage with $a_{\mathrm{CDOM}}(400)$ and salinity fields within estuary and coastal areas. The cause of such errors associated with the SAC algorithm could be attributed to the nearly zero and improbable negative $R_{r s}$ values that occurred as a result of excessive aerosol path radiance removal in the visible bands due to the overestimated $\varepsilon=\rho_{a s}(765) / \rho_{a s}(865)$ in highly turbid and productive waters (McClain et al., 2000; Shanmugam and Ahn, 2007). Such problems were actually manifested in negative $\mathrm{nL}_{w}$ values obtained from MODIS images using the SAC algorithm, ultimately causing an inaccuracy in the satellite estimates of $a_{\mathrm{CDOM}}(400)$ and salinity, and thus preventing their potential applications for mapping and monitoring the LSW plume in the ECS (Sasaki et al., 2008). Avoiding these problems by using a cutoff value of $\mathrm{nL}_{w}$ would, on the other hand, eliminate a large number of the useful pixels toward the estuary and coast from where the LSW plume starts to dominate the colour of the ECS (Sasaki et al., 2008).

Figure 10 allows one to closely examine the spatial variability of $a_{\mathrm{CDOM}}$ (400) and salinity along a transect running across the LSW plume from bright coastal waters in the YR estuary to dark open ocean waters in the Kuroshio Current region (black line on the salinity image in Fig. 9). Transect 
comparison of these properties showed that the agreement of SeaWiFS-SAC retrievals of $a_{\mathrm{CDOM}}(400)$ and salinity was stronger in the Kuroshio Current region where these values approached $0.1 \mathrm{~m}^{-1}$ (and even below) and $34 \mathrm{psu}$, respectively. However, extending comparisons from offshore toward the estuary area revealed that $a_{\mathrm{CDOM}}(400)$ and salinity distributions inferred from these two atmospheric correction schemes significantly differed when delivery by the YR and CCC during 5 April 2005 affected the $a_{\mathrm{CDOM}}(400)$ values greater than $0.6 \mathrm{~m}^{-1}$ and salinity lower than $28 \mathrm{psu}$. This results in large errors when $a_{\mathrm{CDOM}}(400)$ is $>0.8 \mathrm{~m}^{-1}$ and salinity is $<26 \mathrm{psu}$, delivered by the SAC algorithm. Nevertheless, there was good consistency between these two atmospheric correction algorithms over relatively clear regions, with a mean difference of 0.009 in $a_{\mathrm{CDOM}}(400)\left(\mathrm{m}^{-1}\right)$ and 0.096 in salinity (psu).

In addition, we also assessed the performance of our nonlinear salinity model (NLSM) in comparison with the results of the linear salinity model (LSM) developed by Sasaki et al. (2008) and in-situ observations of Chen et al. (2006) and NFRDI (http://www.nfrdi.re.kr/page?id=kr_index). We applied these two models to the SeaWiFS image of 10 May 2001 and compared the predicted salinities around the LSW plume, YS and Kuroshio (arrow marks on the salinity image of 10 May 2001 in Fig. 8). It is important to note that salinity estimations from the NLSM substantially differed with those from the LSM in these three water types, being closely consistent with in-situ observations made by Chen et al. (2006) and NFRDI during the spring (Fig. 11; Table 3). In contrast, salinities predicted by the LSM were always lower than those predicted by the NLSM and observed by Chen et al. (2006) and NFRDI, and this underestimation was the largest from warmer Kuroshio toward colder YR estuary waters: i.e. $1.4 \mathrm{psu}$ in the Kuroshio, $2.8 \mathrm{psu}$ in the YS and $5.6 \mathrm{psu}$ in the LSW plume regions. This discrepancy was likely caused by the LSM because it was derived from the limited number of salinity and CDOM data collected from the restricted range of waters offshore of the ECS. The underestimation was also manifested in their satellite-derived salinity from the LSM at several locations (including the areas affected by aerosols and clouds) and was partly attributed to by the problems of atmospheric correction in these waters.

\subsection{Nature of the CDOM pool}

To identify the nature of the CDOM pool, we applied Eqs. (3) and (4) to the SeaWiFS image of 10 May 2001 for producing an image of the areal distribution of CDOM absorption slope coefficient (a proxy for changes in the CDOM composition) in the ECS. The slope coefficients calculated using the $a_{\mathrm{CDOM}}$ at $400 \mathrm{~nm}$ and $412 \mathrm{~nm}$ were generally in good agreement with measured values at various stations in the ECS and in waters of other similar environments (Bricaud et al., 1981; Davies-Colley, 1992; Green and Blough, 1994; Kowalczuk et al., 2005). This coefficient, largely indepen-
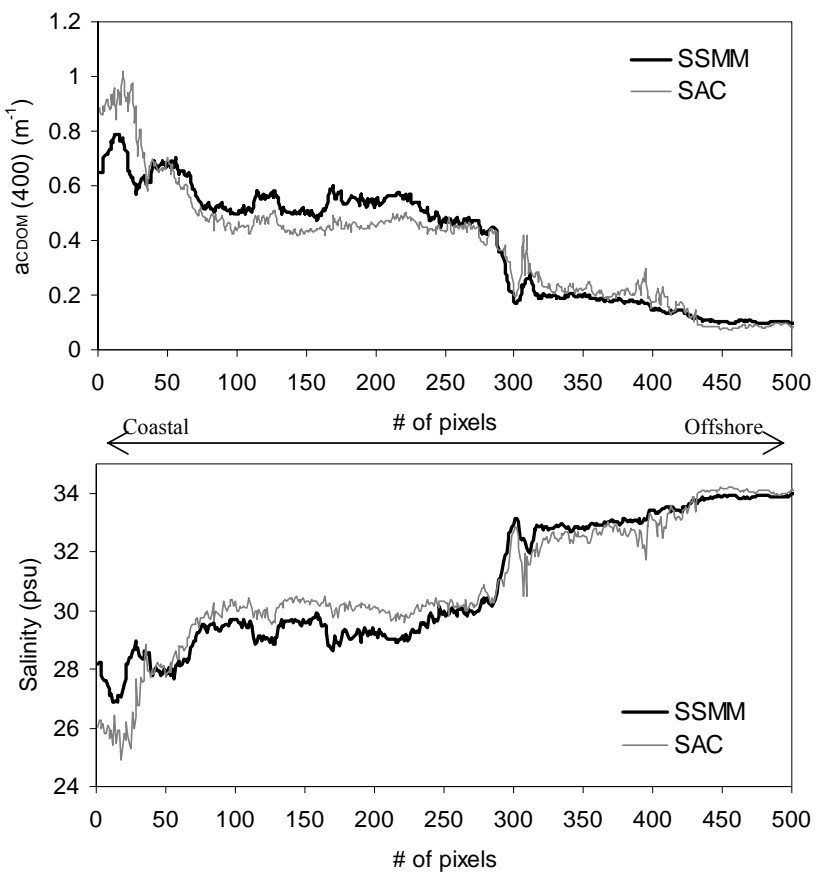

Fig. 10. Horizontal profiles from the SeaWiFS image of 5 April 2005 illustrating the spatial variability of $a_{\mathrm{CDOM}}(400)\left(\mathrm{m}^{-1}\right)$ and salinity (psu) fields along a transect running across the LSW plume from bright coastal waters in the YR estuary to dark ocean waters in the vicinity of the Kuroshio (black line on the salinity image in Fig. 9). SAC - standard atmospheric correction scheme, and SSMM - spectral shape matching method scheme.

dent of wavelength, varied from about $-0.007 \mathrm{~nm}^{-1}$ in clear oceanic waters offshore to $-0.016 \mathrm{~nm}^{-1}$ in highly turbid (CDOM-dominated) waters around the mouth and estuary of the YR. This trend of the increased slope coefficient in offshore waters (due to photobleacing) and decreased slope coefficient (due to the terrestrial CDOM pool) in coastal waters is consistent with that inferred from the SeaWiFS observations in the Georgia Bight (Johannessen et al., 2003), suggesting that the methods presented in Eqs. (3) and (4) predict changes in the CDOM composition in ECS waters. By examining the areal distribution of the slope coefficient in Fig. 12, it is clear that the patterns of riverine and marine CDOM pools are well distinguished by high $a_{\mathrm{CDOM}}$ (400) $\left(>0.4 \mathrm{~m}^{-1}\right)$ with low slope values $\left(<-0.15 \mathrm{~nm}^{-1}\right)$ and low $a_{\mathrm{CDOM}}(400)\left(<0.15 \mathrm{~m}^{-1}\right)$ with high slope values $\left(>-0.015 \mathrm{~nm}^{-1}\right)$, respectively.

\section{Discussion and conclusion}

In the ECS, variability in CDOM absorption has been strongly linked to seasonal cycles of water column mixing (winter-spring) and river discharge (spring-summer) (Ahn et al., 2004; Guo et al., 2007). During the spring, CDOM rise to higher levels as a result of a lack of obvious photochemical 


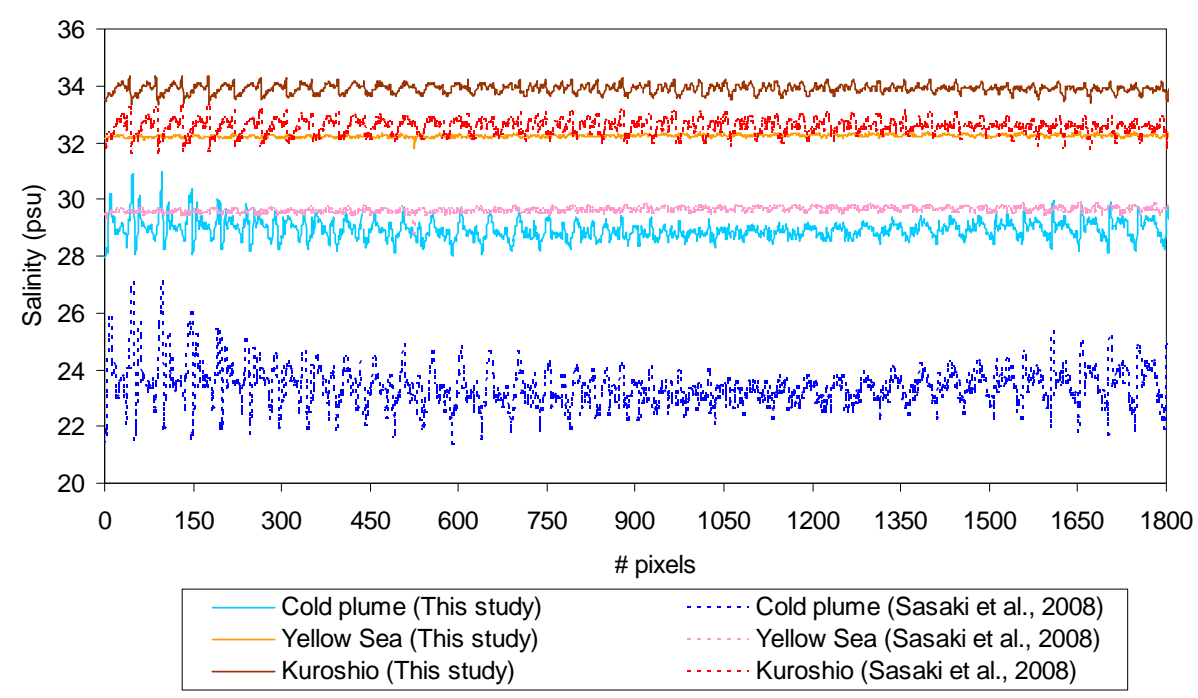

Fig. 11. Comparison of salinity estimations from the nonlinear model (this study) and linear model (proposed by Sasaki et al., 2008) applied to SeaWiFS image of 10 May 2001 at three water types (YR estuary, YS and Kuroshio waters). Mean salinity from the NLSM is 28.9 psu in the LSW plume, 32.2 psu in the YS, and 33.9 psu in the Kuroshio region, whereas mean salinity from the LSM is 23.3 psu in the LSW plume, $29.4 \mathrm{psu}$ in the YS, and $32.5 \mathrm{psu}$ in the Kuroshio region. The linear model is expressed as: Salinity $(\mathrm{psu})=-19.5 \times a_{\mathrm{CDOM}}(400)\left(\mathrm{m}^{-1}\right)+34.5$ (with $R^{2}=0.66$ and $N=43$ ).

Table 3. Seasonal average of the YR discharge $\left(\mathrm{m}^{3} \mathrm{~s}^{-1}\right)$ and salinity (psu) derived from in-situ observations during 1991-2000 (Chen et al., 2006; NFRDI observations).

\begin{tabular}{lcccc}
\hline Periods & $\begin{array}{c}\text { YR } \\
\text { discharge }\end{array}$ & $\begin{array}{c}\text { Salinity } \\
\text { at LSW plume }\end{array}$ & $\begin{array}{c}\text { Salinity } \\
\text { at YS }\end{array}$ & $\begin{array}{c}\text { Salinity at } \\
\text { Kuroshio }\end{array}$ \\
\hline Spring (March-May) & 25417 & 31 & 32 & 34 \\
Summer (June-August) & 50557 & 28 & 31 & 34 \\
Fall (September-November) & 31520 & 32 & 32 & 34 \\
Winter (December-February) & 14006 & 31.5 & 32 & 34 \\
\hline
\end{tabular}

reactions in the low transparency YR estuary caused by high suspended particulate matter associated with the vertical mixing and riverine/estuarine processes (Guo et al., 2007). Previous studies noted that the magnitude of CDOM absorption is related to variations in the salinity of the LSW plume generated by coupled YR and CCC systems, where the slope coefficient increases with salinity at high salinity region (29$31 \mathrm{psu}$ ) of the YR estuary (Moon et al., 2006, 2007; Guo et al., 2007). Such behavior and properties within this region could be synoptically mapped and used with other oceanographic parameters to understand the dynamics of the outflowing plume of freshwater which carries loads of particulate and dissolved substances onto the continental shelf and slope downstream side of Korea, where they strongly influence the colour of the ocean signal recorded by satellite sensors.

Satellite remote sensing offers the environmental community a tool that can synoptically monitor coastal waters at regional and smaller spatial scales. In particular, the data available from the new generation of ocean colour sensors (e.g. SeaWiFS and MODIS) provide a more dense (nearglobal coverage every 2 days) series of images with improved sensor characteristics and processing algorithms (Kahru and Mitchell, 2001). Of these, the SeaWiFS has a band in the short wavelength visible domain $(412 \mathrm{~nm})$ that may be effectively used to estimate CDOM absorption distinct from the other in-water constituents (Carder et al., 1999) and through which to estimate salinity (Moon et al., 2006, 2007). Although the satellite-derived CDOM abundance seems to be a promising parameter for detecting and characterizing the LSW plume, there is difficulty in developing and applying such algorithms (including atmospheric correction) for predicting the CDOM variability around this LSW plume, mainly because of the interferences of CDOM and phytoplankton absorptions with the atmospheric correction of satellite data at shorter wavelengths. This strongly impacts 
the accuracy of salinity retrievals from the satellite data. For example, this was particularly apparent in the recent study of the CDOM and salinity variability around the LSW plume region of the ECS using MODIS imagery (Sasaki et al., 2008), whereas their estimates of $a_{\mathrm{CDOM}}$ (400) and salinity were partly or fully disputed at many locations around the edges of clouds and aerosols as being caused by errors due to the atmospheric correction algorithm. Moreover, salinity predicted by their linear model was also significantly underestimated within the LSW plume region.

Using our regional in-situ data set of the inherent and apparent optical properties (i.e. $R_{r s}$ and $a_{\mathrm{CDOM}}$ ), we established the empirical relationships in this study for remotely estimating CDOM absorption and salinity within the LSW plume region of the ECS. These relationships were validated with in-situ data and the errors were relatively small and acceptable for remote sensing of the LSW plume in the ECS. When applied together with the SSMM, they particularly provide better estimates of $a_{\mathrm{CDOM}}$ (400) and salinity than the standard algorithms. It should be noted that while these empirical algorithms appear to work satisfactorily in this region, one should be cautious when applying them to other regions where the results would be biased by the influence of high concentrations of chlorophyll/suspended sediments or other properties. This is because the empirical coefficients were derived using a relatively small data set obtained in coastal and estuarine waters with significant terrestrial input and should be changed based on measurements from a wide range of waters with different environments. Nevertheless, we believe that the accuracy of salinity retrievals may be better with the nonlinear model using CDOM absorption at a shorter wavelength $(400 \mathrm{~nm})$ where in-water constituents other than CDOM would have a minimal effect. Thus, it may be likely that the salinity retrievals by this model may show success in other regions under the condition that the atmospheric correction is fully valid.

Because there appears to be reasonable consistency in the shape of the CDOM absorption spectrum in the near UV and visible regions in a wide range of natural waters (Twardowski et al., 2004), a single spectral shape of the CDOM absorption (in the blue) derived from the remotely sensed signals at two wavelengths allows the proposed exponential model to predict the spectral behavior of CDOM absorption that is needed for a variety of remote sensing applications and bio-optical models. The spectral behavior is indeed largely determined by the slope coefficient as a proxy for CDOM composition. In this paper, we have shown that the slope coefficients calculated from the ratio of $a_{\mathrm{CDOM}}$ at $400 \mathrm{~nm}$ and $412 \mathrm{~nm}$ provide the potential for detecting and characterizing the CDOM composition in both coastal and offshore waters of the ECS, where lower slope values corresponded to the terrestrial pool of CDOM resulting from the rivers and runoff, and higher slope values corresponded to the marine pool of CDOM resulting from the heterotrophic processes near the surface. The estimated coefficients were found to be in good

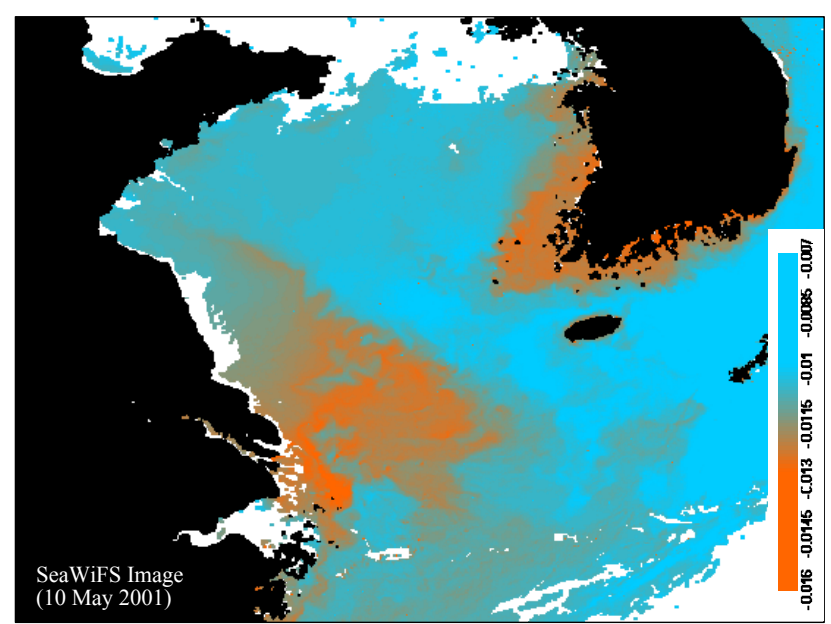

Fig. 12. Slope coefficient (" $S$ " in $\mathrm{nm}^{-1}$ ) of the CDOM absorption spectra estimated from SeaWiFS remote sensing reflectance data (10 May 2001) in the ECS.

agreement with the measured values at various stations in the ECS and in waters of other similar environments (Bricaud et al., 1981; Davies-Colley, 1992; Green and Blough, 1994; Kowalczuk et al., 2005).

In conclusion, this paper examined the feasibility of satellite remote sensing to assess CDOM and salinity, and thus provides great potential in advancing our knowledge of the shelf-slope evolution and migration of LSW plume in the ECS. As CDOM had the strongest influence on the water colour signal and perhaps exhibited significantly smaller time and spatial variability compared with the other in-water constituents, we considered it as a potential for mapping and monitoring the LSW plume in the ECS. The salinity was the bi-product of $a_{\mathrm{CDOM}}(400)$ used for better analysis and interpretation of the LSW plume in both coastal and offshore waters. These analyses showed that the variation and extent of the LSW plume were clearly distinguishable within the regions of YR river discharge and CCC water using SeaWiFS image data. After the development, the LSW plume was seen to be advected eastward by the influence of the YRDW and TaWC, affecting the shelf-slope waters downstream side of Korea. Thus, this study has led to a better understanding of the spatial and temporal variability with the LSW plume during the springtime and would be helpful to address several of the environmental and oceanographic issues associated with its evolution and migration in the shelf-slope waters of the ECS.

Acknowledgements. This research work was supported by the Ministry of Land Transport and Maritime Affairs (MLTM) (KORDI contract numbers PM 512-00 and PM 514-00) as a part of the development of the first Geostationary Ocean Colour Imager (GOCI) for monitoring the ocean environment of this Northwest Pacific Region. We are grateful to the anonymous reviewers for their constructive comments. 
Topical Editor S. Gulev thanks one anonymous referee for her/his help in evaluating this paper.

\section{References}

Ahn, Y. H., Shanmugam., and Gallegos, S.: Evolution of suspended sediment patterns in the East and Yellow Seas, J. Korean Soc. Oceanogr., 39, 26-34, 2004.

Ahn, Y. H. and Shanmugam, P.: New methods for correcting the atmospheric effects in Landsat imagery over turbid (Case-2) waters, Korean J. Rem. Sens., 20, 289-305, 2004.

Austin, R. W.: Inherent spectral radiance signatures of the ocean surface, in: Ocean colour analysis Scripps Institute of Oceanography, La Jolla, CA, 1974.

Beardsely, R. C., Limeburner, R., Yu, H., and Cannon, G. A.: Discharge of the Changjiang (Yangtze River) into the East China Sea, Cont. Shelf Res., 4, 57-76, 1985.

Belanger, S., Babin, M., and Larouche, P.: An empirical algorithm for estimating the contribution of chromophoric dissolved organic matter to total light absorption in optically complex waters, J. Geophys. Res., 113, C04027, doi:10.1029/2007JC004436, 2008.

Binding, C. E. and Bowers, D. G.: Measuring the salinity of the Clyde Sea from remotely sensed ocean colour, Estuarine, Coastal Shelf Sci., 57, 605-611, 2003.

Bowers, D. G., Harker, G. E. L., Smith, P. S. D., and Tett, P.: Optical properties of a region of freshwater influence (the Clyde Sea), Estuarine, Coastal Shelf Sci., 50, 717-726, 2000.

Bowers, D. G., Evans, D., Thomas, D. N., Ellis, K., and Williams, P. J. B.: Interpreting the colour of an estuary, Estuarine, Coastal Shelf Sci., 59, 13-20, 2004.

Boss, E., Pegau, W. S., Zaneveld, R. V., and Barnard, A. H.: Spatial and temporal variability of absorption by dissolved material at a continental shelf, J. Geophys. Res., 106, 9499-9507, 2001.

Bricaud, A., Morel, A., and Prieur, L.: Absorption by dissolved organic matter of the sea (yellow substance) in the UV and visible domains, Limnol. Oceanogr., 26, 43-53, 1981.

Carder, K. L., Chen, F. R., Lee, Z. P., and Hawes, S. K.: Semianalytic Moderate-Resolution Imaging Spectrometer algorithms for chlorophyll $a$ and absorption with bio-optical domains based on nitrate depletion temperatures, J. Geophys. Res., 104, 5403$5421,1999$.

Chen, C., Zhu, J., Beardsley, R. C., and Franks, P. J. S.: Physical-biological sources for dense algal blooms near the Changjiang River, Geophys. Res. Lett., 30(10), 1515, doi:10.1029/2002GL016391, 2003.

Chen, X., Wang, X., and Guo, J.: Seasonal variability of the sea surface salinity in the East China Sea during 1990-2002, J. Geophys. Res., 111, C05008, doi:10.1029/2005JC003078, 2006.

Chen, C., Xue, P., Ding, P., Beardsley, R. C., Xu, Q., Mao, X., Gao, G., Qi, J., Li, C., Lin, H., Cowles, G., and Shi, M.: Physical mechanisms for the offshore detachment of the Changjiang Diluted Water in the East China Sea, J. Geophys. Res., 113, C02002, doi:10.1029/2006JC003994, 2008.

Cheng, M. T., Lin, Y. C., Chio, C. P., Wang, C. F., and Kuo, C. Y.: Characteristics of aerosols collected in central Taiwan during an Asian dust event in spring 2000, Chemosphere, 61, 1439-1450, 2005.
Chester, R.: Marine geochemistry, 698 pp., London, Unwin Hyman Ltd, 1990.

Cullen, J. J., Davis, R. F., Bartlett, J. S., and Miller, W. L.: Toward remote sensing of UV attenuation, photochemical fluxes and biological effects in surface waters, Proc. 1997 Aquatic Sciences Meeting, Santa Fe, NM, USA, ASLO, 1997.

Davies-Colley, R. J.: Yellow substance in coastal and marine waters around the South Island, New Zealand, N.Z., J. Mar. Freshwater Res., 26, 311-322, 1992.

Del Castillo, C. E. and Miller, R. L.: On the use of ocean colour remote sensing to measure the transport of dissolved organic carbon by the Mississippi River Plume, Rem. Sens. Environ., 112, 836-844, 2008.

Doxaran, D., Cherukuru, R. C. N., and Lavender, S. J.: Use of reflectance band ratios to estimate suspended and dissolved matter concentrations in estuarine waters, Int. J. Rem. Sens., 26, 17631769, 2005.

D'Sa, J. D., Steward, R. G., Vodacek, A., Blough, N. V., and Phinney, D.: Determining optical absorption of coloured dissolved organic matter in seawater with a liquid capillary waveguide, Limnol. Oceanogr., 44, 1142-1148, 1999.

D'Sa, E. J. D., Hu, C., Muller-Karger, F. E., and Carder, K. L.: Estimation of coloured dissolved organic matter and salinity fields in case 2 waters using SeaWiFS: Examples from Florida Bay and Florida Shelf, Proc. Indian Acad. Sci. (Earth Planet. Sci.), 111, 197-207, 2002.

Feng, M., Mitsudera, H., and Yoshikawa, Y.: Structure and variability of the Kuroshio Current in Tokara Strait, Phys. Oceanogr., 30, 2257-2276, 2000.

Ferrari, G. M., Dowell, M. D., Grossi, S., and Targa, C.: Relationship between the optical properties of chromophoric dissolved organic matter and total concentration of dissolved organic carbon in the southern Baltic Sea region, Mar. Chem., 55, 299-316, 1996.

Green, S. A. and Blough, N. V.: Optical absorption and fluorescence properties of chromophoric dissolved organic matter in natural waters, Limnol. Oceanogr., 39, 1903-1916, 1994.

Guo, W., Stedmon, C. A., Han, Y., Wu, F., Yu, X., and Hu, M.: The conservative and non-conservative behavior of chromophoric dissolved organic mater in Chinese estuarine waters, Mar. Chem., 107, 357-366, 2007.

He, M. X., Liu, Z. S., Du, K. P., Li, L. P., Chen, R., Carder, K. L, and Lee, Z. P.: Retrieval of chlorophyll from remote-sensing reflectance in the China Seas, Appl. Optics, 39, 2467-2474, 2000.

Hooker, S. B., Firestone, E.., and Acker, J. C.: SeaWiFS Pre-launch Radiometric Calibration and Spectral Characterization, SeaWiFS technical report series, NASA Technical Memorandum 104566, vol. 23, NASA-GFSC, Greenbelt, Maryland, USA, 1994.

Jerlov, N. G.: Optical oceanography, Amsterdam, Elsevier, 1968.

Johannessen, S. C., Miller, W. L., and Cullen, J. J.: Calculation of UV attenuation and coloured dissolved organic matter absorption spectra from measurements of ocean colour, J. Geophys. Res., 108, C9, doi:10.1029/2000JC000514, 2003.

Kahru, M. and Mitchell, B. G.: Seasonal and nonseasonal variability of satellite-derived chlorophyll and coloured dissolved organic matter concentration in the California Current, J. Geophys. Res., 106, 2517-2529, 2001.

Kowalczuk, P., Olszewski, J., Darecki, M., and Kaczmarek, S.: Empirical relationships between coloured dissolved organic matter 
(CDOM) absorption and apparent optical properties in Baltic Sea waters, Int. J. Rem. Sens., 26, 345-370, 2005.

Kutser, T., Pierson, D. C., Kallio, K. Y., Reinart, A., and Sobek, S.: Mapping lake CDOM by satellite remote sensing, Rem. Sens. Environ., 94, 535-540, 2005.

Lie, H. J., Cho, C. H., Lee, J. H., Niiler, P., and Hu, J. H.: Separation of the Kuroshio water and its penetration onto the continental shelf west of Kyushu, J. Geophys. Res., 103, 2963-2976, 1998.

Lie, H. J. and Cho, C. H.: Recent advances in understanding the circulation and hydrography of the East China Sea, Fisheries Oceanogr., 11, 318-328, 2002.

McClain, C. R., Ainsworth, E. J., Barnes, R. A., Eplee, R. E., Patt, F. S., Robinson, W. D., Wang, and Bailey, S. W.: SeaWiFS postlaunch calibration and validation analyses, Part 1, vol. 9, edited by: Hooker, S. B. and Firestone, E. R., NASA Tech. Memo., 2000-206892(2), 82 pp, 2000.

Miller, R. L., Belz, M., Castillo, C. D., and Trzaska, R.: Determining CDOM absorption spectra in diverse coastal environments using a multiple pathlength, liquid core waveguide system, Cont. Shelf Res., 22, 1301-1310, 2002.

Mobley, C. D.: Estimation of the remote sensing reflectance from above-sea surface, Appl. Optics, 38, 7442-7455, 1999.

Monahan, E. C. and Pybus, M. J.: Colour, UV absorbance and salinity of the surface waters of the west coast of Ireland, Nature, 274, 782-784, 1978.

Montes-Hugo, M. A., Carder, K. L., Foy, R. J., Cannizzaro, J., Brown, E., and Pegau, S.: Estimating phytoplankton biomass in coastal waters of Alaska using airborne remote sensing, Rem. Sens. Environ., 98, 481-493, 2005.

Moon, J. E., Yang, C. S., and Ahn, Y. H.: Salinity estimation based on inherent optical property (IOP) in the southern Yellow Sea and northern East China Sea, Proc. 4th JKWOC meeting, 1821 December 2006, Jeju National University, Jeju Island, Korea, 2006.

Moon, J. E., Ahn, Y. H., Ryu, J. H., and Choi, C. K.: Study on the development of $\mathrm{a}_{\text {dom }}$ estimation algorithm by empirical method for GOCI ocean colour sensor, ISRS 2007, 31 October2 November 2007, Jeju, Korea, 2007.

Morel, A., Claustre, H., Antoine, D., and Gentili, B.: Natural variability of bio-optical properties in Case 1 waters: attenuation and reflectance within the visible and near-UV spectral domains, as observed in South Pacific and Mediterranean waters, Biogeosciences, 4, 913-925, 2007,

http://www.biogeosciences.net/4/913/2007/.

Nelson, R. and Guarda, S.: Particulate and dissolved spectral absorption on the continental shelf of the southeastern United States, J. Geophys. Res., 100, 8715-8732, 1995.
Nelson, N. B., Siegel, D. A., Carlson, C. A., Swan, C., Smethie, W. M., and Khatiwala, S.: Hydrography of chromophoric dissolved organic matter in the North Sea, Deep-Sea Res., 54, 710-731, 2007.

O'Reilly, J. E., Moritorena, S., Mitchell, B. G., Seigel, D. S., Carder, K. L., Garver, S. A., Kahru, M., and McClain, C.: Ocean colour chlorophyll algorithms for SeaWiFS, J. Geophys. Res., 103, 24 937-24 953, 1998.

Sasaki, H., Siswanto, S., Nishiuchi, K., Tanaka, K., Hasegawa, T., and Ishizaka, J.: Mapping the low salinity Changjiang diluted water using satellite-retrieved coloured dissolved organic matter $(\mathrm{CDOM})$ in the East China Sea during high river flow season, Geophys. Res. Lett., 35, L04604, doi:10.1029/2007GL032637, 2008.

Shanmugam, P. and Ahn, Y. H.: New atmospheric correction technique to retrieve the ocean colour from SeaWiFS imagery in complex coastal waters, J. Optics A: Pure and Applied Optics, 9, 511-530, 2007.

Shanmugam, P., Ahn, Y. H., and Ram, P. S.: SeaWiFS sensing of hazardous algal blooms and their underlying mechanisms in shelf-slope waters of the North West Pacific during summer, Rem. Sens. Environ., 112, 3248-3270, 2008.

Siegel, D. A., Maritorena, S., Nelson, N. B., Hansell, D. A., and Lorenzi-Kayser, M.: Global distribution and dynamics of coloured dissolved and detrital organic materials, J. Geophys. Res., 107, C12, doi:10.1029/2001JC000965, 2002.

Stedmon, C. A. and Markager, S.: The optics of chromophoric dissolved organic matter (CDOM) in the Greenland Sea: An algorithm for differentiation between marine and terrestrially derived organic matter, Limnol. Oceanogr., 46, 2087-2093, 2001.

Tang, J.: The in-water algorithms of ocean colour for Yellow Sea, YOC-III/YSLME meeting, 20 January 2008, Japan, 2008.

Twardowski, M. S. and Donaghay, P. L.: Separating in-situ and terrigenous sources of absorption by dissolved materials in coastal waters, J. Geophys. Res., 106, 2545-2560, 2001.

Twardowski, M. S., Boss, E., Sullivan, J. M., and Donaghay, P. L.: Modelling the spectral shape of absorption by chromophoric dissolved organic matter, Mar. Chem., 89, 69-88, 2004.

Vodacek, A., Blough, N. V., Degrandpre, M. D., Peltzer, E. T., and Nelson, R. K.: Seasonal variation of CDOM and DOC in the middle Atlantic Bight: terrestrial inputs and photooxidation, Limnol. Oceanogr., 42, 674-686, 1997. 